\title{
MODELLING THE TENSILE DAMAGE AND FRACTURE PROCESSES OF FIBRE-REINFORCED CERAMIC-MATRIX COMPOSITES UNDER THE EFFECT OF PRE-EXPOSURE AT ELEVATED TEMPERATURES
}

\author{
LI LONGBIAO \\ College of Civil Aviation, Nanjing University of Aeronautics and Astronautics, \\ No.29 Yudao St., Nanjing 210016, PR China \\ \#E-mail: 1lb451@nuaa.edu.cn
}

Submitted April 24, 2019, accepted September 16, 2019

\begin{abstract}
Keywords: Ceramic-matrix composites (CMCs), Tensile, Pre-exposure, Matrix cracking, Interface debonding, Fibre failure
In this paper, the tensile damage and fracture process of fibre-reinforced ceramic-matrix composites (CMCs) under the effect of pre-exposure at elevated temperatures are investigated. The damage mechanisms of the interface oxidation and the fibre failure are considered in the stress analysis, matrix multi-cracking, interface debonding and fibre failure. Combining the stress analysis and damage models, the tensile stress-strain curves of the fibre-reinforced CMCs for the different damage stages can be obtained. The effects of the pre-exposure temperature and time, interface shear stress, fibre strength and fibre Weibull modulus on the tensile damage and fracture processes are analysed. The experimental tensile damage and fracture process of the fibre-reinforced CMCs with the different fibre preforms are predicted for the different pre-exposure temperatures and times.
\end{abstract}

\section{INTRODUCTION}

With the rapid development of aerothermodynamics, structural mechanics and material science, turbofan engines with large bypass ratio are developing towards high efficiency, such as low fuel consumption, low emissions, low noise, easy maintenance, high reliability and a long life. Without changing the existing layout of the turbofan engines, relying on innovative materials and novel configurations becomes a fundamental solution. Over the past half century, the thrust-to-weight ratio of commercial aeroengine technology, especially the combustion chamber technology, has significantly improved. At present, the requirements of the high thrust and high thrust-to-weight ratio of the engine are more and more stringent to reduce the emissions of $\mathrm{NO}_{\mathrm{x}}$ and $\mathrm{CO}$. As a result, the turbocharging ratio, turbine inlet temperature, combustion chamber temperature and rotational speed of the engine must also be continuously increased. As far as the materials are concerned, the current high-heat gas of the highefficiency aeroengine has already reached the limit of its operational temperature of the traditional titanium alloy and nickel-based superalloy. The existing alloy material cannot meet the heat-resistant requirements of the next generation of advanced engine design. The high-temperature components have to be protected by air-cooling and a thermal barrier coating. However, the application of air-cooling reduces the combustion efficiency of the engine. In addition, it complicates the structure of the components, which not only increases the difficulty of the processing, but also increases the cost of the development and maintenance. The high performance aero-engine tries to continuously raise the turbine inlet temperature. The high temperature strength, corrosion resistance and anti-oxidation performance of the hot-section components are increasingly in demand. The turbine inlet temperature of engine with a thrust-weight ratio of $15-20$ will reach $1927^{\circ} \mathrm{C}$. Ceramic matrix composites (CMCs) with excellent properties such as high temperature resistance, low density, metal-like fracture behaviour, insensitivity to cracks, and no catastrophic damage, can replace the superalloys to meet the needs of the hot-section components in the higher temperature environments of an aero engine. It is not only beneficial to greatly reduce weight, but it also can save the cooling air or even need no cooling, thus increasing the total pressure ratio, and further increasing the working temperature by about $400-500{ }^{\circ} \mathrm{C}$, and reduces the structural weight around $50-70 \%$ compared with the traditional superalloy [1, 2, 3, 4].

Under tensile loading of the fibre-reinforced $\mathrm{CMCs}$, the tensile stress-strain curve can be divided into four stages, i.e., (1) the linear-elastic stage, the strain increases in direct proportion to the stress; (2) the damage stage with matrix cracking and fibre debonding at the interface, which makes the CMCs appear to have the characteristics of pseudo-plastic fracture and high toughness; (3) the damage stage with saturation of the matrix cracking and complete interface debonding; and (4) the fibre failure stage. Many researchers have investigated the tensile behaviour of fibre-reinforced CMCs. Li et al. [5, 6, 7] investigated the tensile behaviour of unidirectional, cross-ply, 2D and 2.5D CMCs at room 
temperature. The damage models of the matrix cracking, interface debonding and fibre failure were considered and combined with a shear-lag model to predict the tensile stress-strain curves of the fibre-reinforced CMCs with different fibre preforms. Wang et al. [8] compared the tensile behaviour of 1D (unidirectional), 2D (plain woven) and $3 \mathrm{D}$ (braided) $\mathrm{C} / \mathrm{SiC}$ composites at room temperature. The tensile stress-strain curves of $\mathrm{C} / \mathrm{SiC}$ depended on the fibre volume along the loading direction and the interface properties. Zhang et al. [9] investigated the strength degradation of a $2.5 \mathrm{D} \mathrm{C} / \mathrm{SiC}$ composite after exposure at elevated temperature in air conditions. The composite tensile strength and failure strain decreases after exposure at an elevated temperature. Mei et al. [10] investigated the thermal cyclic damage of a $\mathrm{C} / \mathrm{SiC}$ composite in an oxidising environment. Under thermal cyclic behaviour between the temperature of $900{ }^{\circ} \mathrm{C}$ and $1200{ }^{\circ} \mathrm{C}$ under a constant stress of $62.5 \mathrm{MPa}$, the damage of matrix cracking, fibre debonding, sliding and breaking attributed to the strain increased with thermal cyclic number. At elevated temperatures, the interface oxidation degrades the interface and the fibre properties, which affects the tensile properties of the fibre-reinforced CMCs $[11,12]$. Hou et al. [13] investigated the influence of high temperature exposure to air on the damage to 3D $\mathrm{C} / \mathrm{SiC}$ composites. The composite was exposed in an air atmosphere at the elevated temperatures of $600{ }^{\circ} \mathrm{C}, 900{ }^{\circ} \mathrm{C}$ and $1300{ }^{\circ} \mathrm{C}$ for 0 to $15 \mathrm{~h}$, and then was loaded under a three-point bend test at room temperature. The matrix microcracks caused by a difference of the coefficients of the thermal expansion between the matrix and carbon fibres in the cooling process after the composite preparation acted as oxygen diffuse paths, however, the damage decreased with the temperature at the same exposure time. Wallentine [14] investigated the effect of prior exposure at elevated temperatures on the tensile properties and stress-strain behaviour of different fibre-reinforced $\mathrm{CMCs}$, i.e., $\mathrm{SiC} / \mathrm{SiNC}$, $\mathrm{C} / \mathrm{SiC}, \mathrm{C} / \mathrm{SiC}-\mathrm{B}_{4} \mathrm{C}$ and $\mathrm{SiC} / \mathrm{SiC}-\mathrm{B}_{4} \mathrm{C}$. The CMCs were heat treated in laboratory air for $10 \mathrm{~h}, 20 \mathrm{~h}, 40 \mathrm{~h}$ and $100 \mathrm{~h}$ at over-temperatures $\left(1300^{\circ} \mathrm{C}\right.$ or $\left.1400^{\circ} \mathrm{C}\right)$ and for $100 \mathrm{~h}$ at the operating temperature $\left(1200^{\circ} \mathrm{C}\right.$ or $\left.1300^{\circ} \mathrm{C}\right)$, and then tensile loaded to failure at room temperature. The prior exposure at the elevated temperature caused a reduction in the tensile strength and changed the tensile stress-strain behaviour due to the oxidation of the inter-phase and fibres. Gowayed et al. [15] investigated the effect of oxidation on the strain accumulation of

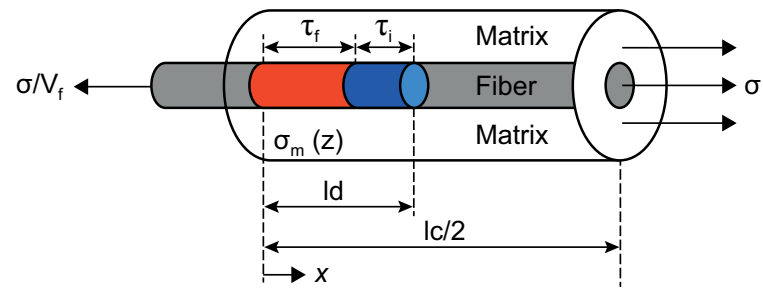

Figure 1. The unit cell of the shear-lag model.
$\mathrm{SiC} / \mathrm{SiNC}$ and $\mathrm{SiC} / \mathrm{SiC}$ composites under dwell-fatigue loading. The stress level and cracking density affected the internal damage and accumulation strain. However, the tensile and damage fracture processes of the fibrereinforced CMCs under the effect of pre-exposure at elevated temperatures have not been investigated.

In this paper, the tensile damage and fracture process of the fibre-reinforced CMCs under the effect of pre-exposure at elevated temperatures are investigated. The damage mechanisms of the interface oxidation and fibre failure are considered in the stress analysis, matrix multi-cracking, interface debonding and fibre failure. Combining the stress analysis and damage models, the tensile stress-strain curves of the fibre-reinforced CMCs for the different damage stages can be obtained. The effects of the pre-exposure temperatures and time, interface shear stress, fibre strength and fibre Weibull modulus on the tensile damage and fracture processes are analysed. The experimental tensile damage and the fracture process of the fibre-reinforced CMCs with different fibre preforms are predicted for the different pre-exposure temperatures and times.

\section{THEORETICAL}

As the mismatch of the axial thermal expansion coefficient between the carbon fibre and the silicon carbide matrix, there are unavoidable microcracks within the $\mathrm{SiC}$ matrix when the composite is cooled down from the high fabricated temperature to the ambient temperature. These processing-induced microcracks mainly exist in the surface of the material, which do not propagate through the entire thickness of the composite. However, at an elevated temperature, the microcracks serve as avenues for the ingress of the environmental atmosphere into the composite. The oxygen reacts with the carbon layer along the fibre length at a certain rate of $\mathrm{d} \zeta / \mathrm{d} t$, in which $\zeta$ is the length of the carbon lost on each side of the crack. [16]

$$
\zeta(t)=\varphi_{1}\left[1-\exp \left(-\frac{\varphi_{2} t}{b}\right)\right]
$$

where $b$ is a delay factor considering the deceleration of the reduced oxygen activity; and $\varphi_{1}$ and $\varphi_{2}$ are the parameters dependent on the temperature and described using Arrhenius type laws.

$$
\begin{gathered}
\varphi_{1}=7.021 \times 10^{-3} \times \exp \left(\frac{8231}{T}\right) \\
\varphi_{2}=227.1 \times \exp \left(-\frac{17090}{T}\right)
\end{gathered}
$$

where $\varphi_{1}$ is in $\mathrm{mm}$ and $\varphi_{2}$ in $\mathrm{s}^{-1} ; \varphi_{1}$ represents the asymptotic behaviour for long times, which decreases with the temperature; and the product $\varphi_{1} \varphi_{2}$ represents the initial oxidation rate, which is an increasing function of the temperature. 


\section{Stress analysis considering the interface oxidation and fibre failure}

When the matrix cracking and interface debonding damage occur in the fibre-reinforced CMCs, the shearlag model can be used to analyse the micro stress distributions in the interface oxidation region, interface slip region and interface bonded region, as shown in Figure 1. The distributions of the fibre and matrix axial stress distribution, and the fibre/matrix interface shear stress can be determined using the following equations.

$$
\sigma_{\mathrm{f}}(x)=\left\{\begin{array}{l}
\frac{\sigma}{V_{\mathrm{f}}}-\frac{2 \tau_{\mathrm{f}}}{r_{\mathrm{f}}} x, x \in[0, \zeta(t)] \\
\frac{\sigma}{V_{\mathrm{f}}}-\frac{2 \tau_{\mathrm{f}}}{r_{\mathrm{f}}} \zeta(t)-\frac{2 \tau_{\mathrm{i}}}{r_{\mathrm{f}}}[x-\zeta(t)], x \in\left[\zeta(t), l_{\mathrm{d}}\right] \\
\sigma_{\mathrm{fo}}+\left\{\frac{\sigma}{V_{\mathrm{f}}}-\frac{2 \tau_{\mathrm{f}}}{r_{\mathrm{f}}} \zeta(t)-\frac{2 \tau_{\mathrm{i}}}{r_{\mathrm{f}}}\left[l_{\mathrm{d}}-\zeta(t)\right]-\sigma_{\mathrm{fo}}\right\} \exp \left(-\rho \frac{x-l_{\mathrm{d}}}{r_{\mathrm{f}}}\right), x \in\left[l_{\mathrm{d}}, \frac{l_{\mathrm{c}}}{2}\right]
\end{array}\right.
$$

$$
\sigma_{\mathrm{m}}(x)=\left\{\begin{array}{l}
2 \frac{V_{\mathrm{f}}}{V_{\mathrm{m}}} \frac{\tau_{\mathrm{f}}}{r_{\mathrm{f}}} x, x \in[0, \zeta(t)] \\
2 \frac{V_{\mathrm{f}}}{V_{\mathrm{m}}} \frac{\tau_{\mathrm{f}}}{r_{\mathrm{f}}} \zeta(t)+2 \frac{V_{\mathrm{f}}}{V_{\mathrm{m}}} \frac{\tau_{\mathrm{f}}}{r_{\mathrm{f}}}[x-\zeta(t)], x \in\left[\zeta(t), l_{\mathrm{d}}\right] \\
\sigma_{\mathrm{mo}}+\left\{2 \frac{V_{\mathrm{f}}}{V_{\mathrm{m}}} \frac{\tau_{\mathrm{f}}}{r_{\mathrm{f}}} \zeta(t)+2 \frac{V_{\mathrm{f}}}{V_{\mathrm{m}}} \frac{\tau_{\mathrm{i}}}{r_{\mathrm{f}}}\left[l_{\mathrm{d}}-\zeta(t)\right]-\sigma_{\mathrm{mo}}\right\} \exp \left(-\rho \frac{x-l_{\mathrm{d}}}{r_{\mathrm{f}}}\right), x \in\left[l_{\mathrm{d}}, \frac{l_{\mathrm{c}}}{2}\right]
\end{array}\right.
$$

$$
\tau_{\mathrm{i}}(x)=\left\{\begin{array}{l}
\tau_{\mathrm{f}}, x \in[0, \zeta(t)] \\
\tau_{\mathrm{i}}, x \in\left[\zeta(t), l_{\mathrm{d}}\right] \\
\frac{\rho}{2}\left\{\frac{\sigma}{V_{\mathrm{f}}}-\frac{2 \tau_{\mathrm{f}}}{r_{\mathrm{f}}} \zeta(t)-\frac{2 \tau_{\mathrm{i}}}{r_{\mathrm{f}}}\left[l_{\mathrm{d}}-\zeta(t)\right]-\sigma_{\mathrm{fo}}\right\} \exp \left(-\rho \frac{x-l_{\mathrm{d}}}{r_{\mathrm{f}}}\right), x \in\left[l_{\mathrm{d}}, \frac{l_{\mathrm{c}}}{2}\right]
\end{array}\right.
$$

where $V_{\mathrm{f}}$ and $V_{\mathrm{m}}$ denote the fibre and matrix volume, respectively; $\tau_{\mathrm{f}}$ and $\tau_{\mathrm{i}}$ denote the interface shear stress in the interface oxidation region and interface de-bonded region, respectively; $r_{\mathrm{f}}$ denotes the fibre radius; $l_{\mathrm{d}}$ and $l_{\mathrm{c}}$ denote the interface de-bonded length and the matrix crack spacing, respectively; $\rho$ denotes the shearlag model parameter; and $\sigma_{\mathrm{fo}}$ and $\sigma_{\mathrm{mo}}$ denote the fibre and matrix axial stress in the interface bonded region, respectively.

$$
\begin{gathered}
\sigma_{\mathrm{fo}}=\frac{E_{\mathrm{f}}}{E_{\mathrm{c}}} \sigma+E_{\mathrm{f}}\left(\alpha_{\mathrm{c}}-\alpha_{\mathrm{f}}\right) \Delta \mathrm{T} \\
\sigma_{\mathrm{mo}}=\frac{E_{\mathrm{m}}}{E_{\mathrm{c}}} \sigma+E_{\mathrm{m}}\left(\alpha_{\mathrm{c}}-\alpha_{\mathrm{m}}\right) \Delta \mathrm{T}
\end{gathered}
$$

where $E_{\mathrm{f}}, E_{\mathrm{m}}$ and $E_{\mathrm{c}}$ denote the fibre, matrix and composite elastic modulus, respectively; $\alpha_{\mathrm{f}}, \alpha_{\mathrm{m}}$ and $\alpha_{\mathrm{c}}$ denote the fibre, matrix and composite thermal expansion coefficient, respectively; and $\Delta T$ denotes the temperature difference between the testing temperature and fabrication temperature.

When a fibre failure occurs, the fibre axial stress in the interface de-bonded and bonded region can be determined using the following equation.

$$
\sigma_{\mathrm{f}}(x)=\left\{\begin{array}{l}
T-\frac{2 \tau_{\mathrm{f}}}{r_{\mathrm{f}}} x, x \in[0, \zeta(t)] \\
T-\frac{2 \tau_{\mathrm{f}}}{r_{\mathrm{f}}} \zeta(t)-\frac{2 \tau_{\mathrm{i}}}{r_{\mathrm{f}}}[x-\zeta(t)], x \in\left[\zeta(t), l_{\mathrm{d}}\right] \\
\sigma_{\mathrm{fo}}+\left\{T-\frac{2 \tau_{\mathrm{f}}}{r_{\mathrm{f}}} \zeta(t)-\frac{2 \tau_{\mathrm{i}}}{r_{\mathrm{f}}}\left[l_{\mathrm{d}}-\zeta(t)\right]-\sigma_{\mathrm{fo}}\right\} \exp \left(-\rho \frac{x-l_{\mathrm{d}}}{r_{\mathrm{f}}}\right), x \in\left[l_{\mathrm{d}}, l_{\mathrm{c}}\right]
\end{array}\right.
$$

where $T$ denotes the intact fibre stress.

\section{Matrix multi-cracking considering the interface oxidation}

The two-parameter Weibull distribution is used to describe the tensile strength of the matrix, and the failure probability of the matrix can be determined using the following Equation. [17]

$$
P_{\mathrm{m}}=1-\exp \left\{-\left[\frac{\sigma-\left(\sigma_{\mathrm{mc}}-\sigma_{\mathrm{th}}\right)}{\left(\sigma_{\mathrm{R}}-\sigma_{\mathrm{th}}\right)-\left(\sigma_{\mathrm{mc}}-\sigma_{\mathrm{th}}\right)}\right]^{m}\right\}
$$

where $\sigma_{\mathrm{R}}$ denotes the matrix characteristic strength; $\sigma_{\mathrm{mc}}$ denotes the matrix first cracking stress; $\sigma_{\text {th }}$ denotes the matrix thermal residual stress; and $m$ denotes the matrix Weibull modulus.

When the applied stress increases, the matrix cracking density increases. The matrix failure probability is related to the instantaneous matrix crack space and saturation matrix crack spacing, as follows:

$$
P_{\mathrm{m}}=l_{\mathrm{sat}} / l_{\mathrm{c}}
$$

where

$$
l_{\mathrm{sat}}=\Lambda\left(\sigma_{\mathrm{mc}} / \sigma_{\mathrm{R}}, \sigma_{\mathrm{th}} / \sigma_{\mathrm{R}}, \mathrm{m}\right) \delta_{\mathrm{R}}
$$

where $\Lambda$ denotes the final nominal crack space, which is a pure number and only depends on the micromechanical and statistical quantities characterising the cracking; and $\delta_{R}$ denotes the characteristic interface sliding length.

$$
\delta_{\mathrm{R}}=\frac{r_{\mathrm{f}}}{2 \tau_{\mathrm{i}}} \frac{V_{\mathrm{m}} E_{\mathrm{m}}}{V_{\mathrm{f}} E_{\mathrm{c}}} \sigma_{\mathrm{R}}+\left(1-\frac{\tau_{\mathrm{f}}}{\tau_{\mathrm{i}}}\right) \zeta(t)
$$

Using Equations 10-13, the instantaneous matrix cracking space can be determined using the following equation.

$l_{\mathrm{c}}=r_{\mathrm{f}} \frac{V_{\mathrm{m}} E_{\mathrm{m}}}{V_{\mathrm{f}} E_{\mathrm{c}}} \frac{\sigma_{\mathrm{R}}}{2 \tau_{\mathrm{i}}} \Lambda\left\{1-\exp \left[-\left(\frac{\sigma-\left(\sigma_{\mathrm{mc}}-\sigma_{\mathrm{th}}\right)}{\left(\sigma_{\mathrm{R}}-\sigma_{\mathrm{th}}\right)-\left(\sigma_{\mathrm{mc}}-\sigma_{\mathrm{th}}\right)}\right)^{m}\right]\right\}^{-1}$

\section{Interface debonding considering the interface oxidation}

When the matrix cracking propagates to the fibre/ matrix interface, the fracture mechanics approach is used to determine the interface de-bonded length [18].

$$
\xi_{\mathrm{d}}=-\frac{F}{4 \pi r_{\mathrm{f}}} \frac{\partial w_{\mathrm{f}}(x=0)}{\partial l_{\mathrm{d}}}-\frac{1}{2} \int_{0}^{l_{\mathrm{d}}} \tau_{\mathrm{i}} \frac{\partial v(x)}{\partial l_{\mathrm{d}}} d x
$$


where $\xi_{\mathrm{d}}$ denotes the interface de-bond energy; $F(=$ $\left.=\pi r_{\mathrm{f}}^{2} \sigma / V_{\mathrm{f}}\right)$ denotes the fibre stress on the matrix cracking plane; $w_{\mathrm{f}}(x=0)$ denotes the fibre axial displacement at the matrix cracking plane; and $v(x)$ denotes the relative displacement between the fibre and the matrix.

$$
\begin{aligned}
w_{\mathrm{f}}(x)= & \int_{x}^{l_{\mathrm{c}} / 2} \frac{\sigma_{\mathrm{f}}(x)}{E_{\mathrm{f}}} d x \\
= & \frac{\sigma}{V_{\mathrm{f}} E_{\mathrm{f}}}\left(l_{\mathrm{d}}-x\right)-\frac{\tau_{\mathrm{f}}}{r_{\mathrm{f}} E_{\mathrm{f}}}\left[2 \zeta(t) l_{\mathrm{d}}-\zeta^{2}-x^{2}\right]-\frac{\tau_{\mathrm{i}}}{r_{\mathrm{f}} E_{\mathrm{f}}}\left[l_{\mathrm{d}}-\zeta(t)\right]^{2}+\frac{\sigma_{\mathrm{fo}}}{E_{\mathrm{f}}}\left(\frac{l_{\mathrm{c}}}{2}-l_{\mathrm{d}}\right) \\
& +\frac{r_{\mathrm{f}}}{\rho E_{\mathrm{f}}}\left[\frac{V_{\mathrm{m}}}{V_{\mathrm{f}}} \sigma_{\mathrm{mo}}-\frac{2 \tau_{\mathrm{f}}}{r_{\mathrm{f}}} \zeta(t)-\frac{2 \tau_{\mathrm{i}}}{r_{\mathrm{f}}}\left(l_{\mathrm{d}}-\zeta(t)\right)\right]\left[1-\exp \left(-\rho \frac{l_{\mathrm{c}} / 2-l_{\mathrm{d}}}{r_{\mathrm{f}}}\right)\right] \\
w_{\mathrm{m}}(x)= & \int_{x}^{l_{\mathrm{f}} / 2} \frac{\sigma_{\mathrm{m}}(x)}{E_{\mathrm{m}}} d x \\
= & \frac{V_{\mathrm{f}} \tau_{\mathrm{f}}}{r_{\mathrm{f}} V_{\mathrm{m}} E_{m}}\left(2 \zeta(t) l_{\mathrm{d}}-\zeta^{2}(t)-x^{2}\right)+\frac{V_{\mathrm{f}} \tau_{\mathrm{i}}}{r_{\mathrm{f}} V_{\mathrm{m}} E_{m}}\left(l_{\mathrm{d}}-\zeta(t)\right)^{2}+\frac{\sigma_{\mathrm{mo}}}{E_{\mathrm{m}}}\left(\frac{l_{\mathrm{c}}}{2}-l_{\mathrm{d}}\right) \\
& -\frac{r_{\mathrm{f}}}{\rho E_{\mathrm{m}}}\left[\sigma_{\mathrm{mo}}-2 \frac{V_{\mathrm{f}} \tau_{\mathrm{f}}}{r_{\mathrm{f}} V_{\mathrm{m}}} \zeta(t)-2 \frac{V_{\mathrm{f}} \tau_{\mathrm{i}}}{r_{\mathrm{f}} V_{\mathrm{m}}}\left(l_{\mathrm{d}}-\zeta(t)\right)\right]\left[1-\exp \left(-\rho \frac{l_{\mathrm{c}} / 2-l_{\mathrm{d}}}{r_{\mathrm{f}}}\right)\right]
\end{aligned}
$$

The relative displacement $\mathrm{v}(\mathrm{x})$ between the fibre and the matrix is described using the following equation.

$$
\begin{aligned}
v(x)= & \left|w_{\mathrm{f}}(x)-w_{\mathrm{m}}(x)\right| \\
= & \frac{\sigma}{V_{\mathrm{f}} E_{\mathrm{f}}}\left(l_{\mathrm{d}}-x\right)-\frac{E_{\mathrm{c}} \tau_{\mathrm{f}}}{r_{\mathrm{f}} V_{\mathrm{m}} E_{\mathrm{m}} E_{\mathrm{f}}}\left(2 \zeta(t) l_{\mathrm{d}}-\zeta^{2}(t)-x^{2}\right)-\frac{E_{\mathrm{c}} \tau_{\mathrm{i}}}{r_{\mathrm{f}} V_{\mathrm{m}} E_{\mathrm{m}} E_{\mathrm{f}}}\left(l_{\mathrm{d}}-\zeta(t)\right)^{2} \\
& +\frac{r_{\mathrm{f}} E_{\mathrm{c}}}{\rho V_{\mathrm{m}} E_{\mathrm{m}} E_{\mathrm{f}}}\left[\sigma_{\mathrm{mo}}-2 \frac{\tau_{\mathrm{f}}}{r_{\mathrm{f}}} \zeta(t)-2 \frac{\tau_{\mathrm{i}}}{r_{\mathrm{f}}}\left(l_{\mathrm{d}}-\zeta(t)\right)\right]\left[1-\exp \left(-\rho \frac{l_{\mathrm{c}} / 2-l_{\mathrm{d}}}{r_{\mathrm{f}}}\right)\right]
\end{aligned}
$$

Substituting $w_{\mathrm{f}}(x=0)$ and $v(x)$ into Equation 15, it leads to the following Equation 19.

$$
\begin{aligned}
& \frac{E_{\mathrm{c}} \tau_{\mathrm{i}}^{2}}{r_{\mathrm{f}} V_{\mathrm{m}} E_{\mathrm{m}} E_{\mathrm{f}}}\left(l_{\mathrm{d}}-\zeta(t)\right)^{2}+\frac{E_{\mathrm{c}} \tau_{\mathrm{i}}^{2}}{\rho V_{\mathrm{m}} E_{\mathrm{m}} E_{\mathrm{f}}}\left(l_{\mathrm{d}}-\zeta(t)\right)- \\
& -\frac{\tau_{\mathrm{i}} \sigma}{V_{\mathrm{f}} E_{\mathrm{f}}}\left(l_{\mathrm{d}}-\zeta(t)\right)+\frac{2 E_{\mathrm{c}} \tau_{\mathrm{f}} \tau_{\mathrm{i}}}{r_{\mathrm{f}} V_{\mathrm{m}} E_{\mathrm{m}} E_{\mathrm{f}}} \zeta(t)\left(l_{\mathrm{d}}-\zeta(t)\right)- \\
& -\frac{r_{\mathrm{f}} \tau_{\mathrm{i}} \sigma}{2 \rho V_{\mathrm{f}} E_{\mathrm{f}}}+\frac{E_{\mathrm{c}} \tau_{\mathrm{f}}^{2}}{r_{\mathrm{f}} V_{\mathrm{m}} E_{\mathrm{m}} E_{\mathrm{f}}} \zeta^{2}(t)+\frac{E_{\mathrm{c}} \tau_{\mathrm{f}} \tau_{\mathrm{i}}}{\rho V_{\mathrm{m}} E_{\mathrm{m}} E_{\mathrm{f}}} \zeta(t)- \\
& -\frac{\tau_{\mathrm{f}} \sigma}{V_{\mathrm{f}} E_{\mathrm{f}}} \zeta(t)+\frac{r_{\mathrm{f}} V_{\mathrm{m}} E_{\mathrm{m}} \sigma^{2}}{4 V_{\mathrm{f}}^{2} E_{\mathrm{f}} E_{\mathrm{c}}}-\xi_{d}=0
\end{aligned}
$$

Solving Equation 19, the interface de-bonded length is determined using the following Equation 20.

$$
\begin{aligned}
l_{\mathrm{d}} & =\left(1-\frac{\tau_{\mathrm{f}}}{\tau_{\mathrm{i}}}\right) \zeta(t)+\frac{r_{\mathrm{f}}}{2}\left(\frac{V_{\mathrm{m}} E_{\mathrm{m}} \sigma}{V_{\mathrm{f}} E_{\mathrm{c}}}-\frac{1}{\rho}\right)- \\
& -\sqrt{\left(\frac{r_{\mathrm{f}}}{2 \rho}\right)^{2}+\frac{r_{\mathrm{f}} V_{\mathrm{m}} E_{\mathrm{m}} E_{\mathrm{f}}}{E_{\mathrm{c}} \tau_{\mathrm{i}}^{2}} \xi_{\mathrm{d}}}
\end{aligned}
$$

Fibre failure considering the interface and fibre oxidation

The two-parameter Weibull model is adopted to describe the fibre strength distribution, and the Global Load Sharing criterion is used to determine the stress distributions between the intact and fracture fibres [19].

$$
\frac{\sigma}{V_{\mathrm{f}}}=T(1-P(T))+\frac{2 \tau_{\mathrm{f}}}{r_{\mathrm{f}}}\langle L\rangle P(T)
$$

where $\langle\mathrm{L}\rangle$ denotes the average fibre pullout length; and $P(T)$ denotes the fibre failure probability.

$$
P(T)=1-\exp \left[-\left(\frac{T}{\sigma_{\mathrm{c}}}\right)^{m_{\mathrm{f}}+1}\right]
$$

where $m_{\mathrm{f}}$ denotes the fibre Weibull modulus; $\sigma_{\mathrm{fc}}$ denotes the fibre characteristic strength of length $\delta_{\mathrm{c}}$ of the fibre.

$$
\sigma_{\mathrm{c}}=\left(\frac{l_{\mathrm{o}} \sigma_{\mathrm{o}}^{m_{\mathrm{f}}} \tau_{\mathrm{i}}}{r_{\mathrm{f}}}\right)^{\frac{1}{m_{\mathrm{f}}+1}}, \delta_{\mathrm{c}}=\left(\frac{\sigma_{\mathrm{o}} r_{\mathrm{f}} \frac{1}{l_{\mathrm{o}}}}{\tau_{\mathrm{i}}}\right)^{\frac{m_{\mathrm{f}}}{m_{\mathrm{f}}+1}}
$$

The time-dependent fibre strength of $\sigma_{o}(t)$ can be determined using the following equation. [20]

$$
\sigma_{0}(t)=\left\{\begin{array}{l}
\sigma_{0}, t \leq \frac{1}{k}\left(\frac{K_{I C}}{Y \sigma_{0}}\right)^{4} \\
\frac{K_{I C}}{Y \sqrt[4]{k t}}, t>\frac{1}{k}\left(\frac{K_{I C}}{Y \sigma_{0}}\right)^{4}
\end{array}\right.
$$

The composite tensile strength is given by the following equation.

$$
\sigma_{\mathrm{UTS}}=V_{\mathrm{f}} \sigma_{\mathrm{c}}\left(\frac{2}{m_{\mathrm{f}}+2}\right)^{\frac{1}{m_{\mathrm{f}}+1}}\left(\frac{m_{\mathrm{f}}+1}{m_{\mathrm{f}}+2}\right)
$$

Tensile stress-strain curves considering the effect of the pre-exposure

For the fibre-reinforced CMCs without damage, the composite strain can be determined using the following Equation 26.

$$
\varepsilon_{\mathrm{c}}=\sigma / E_{\mathrm{c}}
$$

When damage forms inside the CMCs, the composite strain can be determined using the following Equation 27.

$$
\varepsilon_{\mathrm{c}}=\frac{2}{E_{\mathrm{f}} l_{\mathrm{c}}} \int_{l_{\mathrm{c}} / 2} \sigma_{\mathrm{f}}(x) d x-\left(\alpha_{\mathrm{c}}-\alpha_{\mathrm{f}}\right) \Delta \mathrm{T}
$$

When the matrix cracking and interface debonding occurs, the composite strain can be determined using the following Equation 28.

$$
\begin{aligned}
& \varepsilon_{\mathrm{c}}=\frac{2 \sigma}{V_{\mathrm{f}} E_{\mathrm{f}}} \frac{l_{\mathrm{d}}}{l_{\mathrm{c}}}+\frac{2 \tau_{\mathrm{f}}}{r_{\mathrm{f}} E_{\mathrm{f}} l_{\mathrm{c}}} \zeta^{2}(t)-\frac{4 \tau_{\mathrm{f}}}{r_{\mathrm{f}} E_{\mathrm{f}}} \frac{l_{\mathrm{d}}}{l_{\mathrm{c}}} \zeta(t)-\frac{2 \tau_{\mathrm{i}}}{r_{\mathrm{f}} E_{\mathrm{f}} l_{\mathrm{c}}}\left[l_{\mathrm{d}}-\zeta(t)\right]^{2}+\frac{2 \sigma_{\mathrm{fo}}}{E_{\mathrm{f}} l_{\mathrm{c}}}\left(\frac{l_{\mathrm{c}}}{2}-l_{\mathrm{d}}\right) \\
& +\frac{2 r_{\mathrm{f}}}{\rho E_{\mathrm{f}} l_{\mathrm{c}}}\left\{\frac{\sigma}{V_{\mathrm{f}}}-\frac{2 \tau_{\mathrm{f}}}{r_{\mathrm{f}}} \zeta(t)-\frac{2 \tau_{\mathrm{i}}}{r_{\mathrm{f}}}\left[l_{\mathrm{d}}-\zeta(t)\right]-\sigma_{\mathrm{fo}}\right\} \\
& \times\left[1-\exp \left(-\rho \frac{l_{\mathrm{c}} / 2-l_{\mathrm{d}}}{r_{\mathrm{f}}}\right)\right]-\left(\alpha_{\mathrm{c}}-\alpha_{\mathrm{f}}\right) \Delta \mathrm{T}
\end{aligned}
$$

When a fibre failure occurs, the composite strain can be determined using the following Equation 29. 


$$
\begin{aligned}
\varepsilon_{\mathrm{c}}= & \frac{T}{E_{\mathrm{f}}} \frac{2 l_{\mathrm{d}}}{l_{\mathrm{c}}}+\frac{2 \tau_{\mathrm{f}}}{r_{\mathrm{f}} E_{\mathrm{f}} l_{\mathrm{c}}} \zeta^{2}(t)-\frac{4 \tau_{\mathrm{f}} l_{\mathrm{d}}}{r_{\mathrm{f}} E_{\mathrm{f}} l_{\mathrm{c}}} \zeta(t)-\frac{2 \tau_{\mathrm{i}}}{r_{\mathrm{f}} E_{\mathrm{f}} l_{\mathrm{c}}}\left(l_{\mathrm{d}}-\zeta(t)\right)^{2}+\frac{2 \sigma_{\mathrm{fo}}}{E_{\mathrm{f}} l_{\mathrm{c}}}\left(\frac{l_{\mathrm{c}}}{2}-l_{\mathrm{d}}\right) \\
& +\frac{2 r_{\mathrm{f}}}{\rho E_{\mathrm{f}} l_{\mathrm{c}}}\left\{T-\frac{2 \tau_{\mathrm{f}}}{r_{\mathrm{f}}} \zeta(t)-\frac{2 \tau_{\mathrm{i}}}{r_{\mathrm{f}}}\left[l_{\mathrm{d}}-\zeta(t)\right]-\sigma_{\mathrm{fo}}\right\} \\
& \times\left[1-\exp \left(-\rho \frac{l_{\mathrm{c}} / 2-l_{\mathrm{d}}}{r_{\mathrm{f}}}\right)\right]-\left(\alpha_{\mathrm{c}}-\alpha_{\mathrm{f}}\right) \Delta \mathrm{T}
\end{aligned}
$$

For the 2D, 2.5D and 3D CMCs, the effective coefficient of the fibre volume fraction in the direction of loading (ECFL) is defined as:

$$
\lambda=\frac{V_{\mathrm{f}}^{\text {axial }}}{V_{\mathrm{f}}}
$$

where $V_{\mathrm{f}}$ and $V_{\mathrm{f}}^{\text {axial }}$ refer to the total fibre volume fraction in the composites and the effective fibre volume fraction in the direction of axial tensile loading.

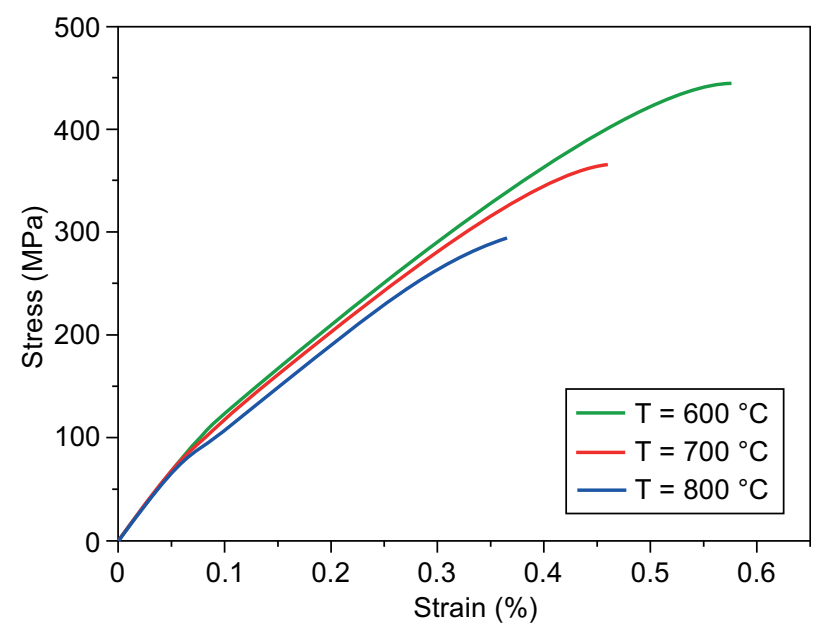

a)

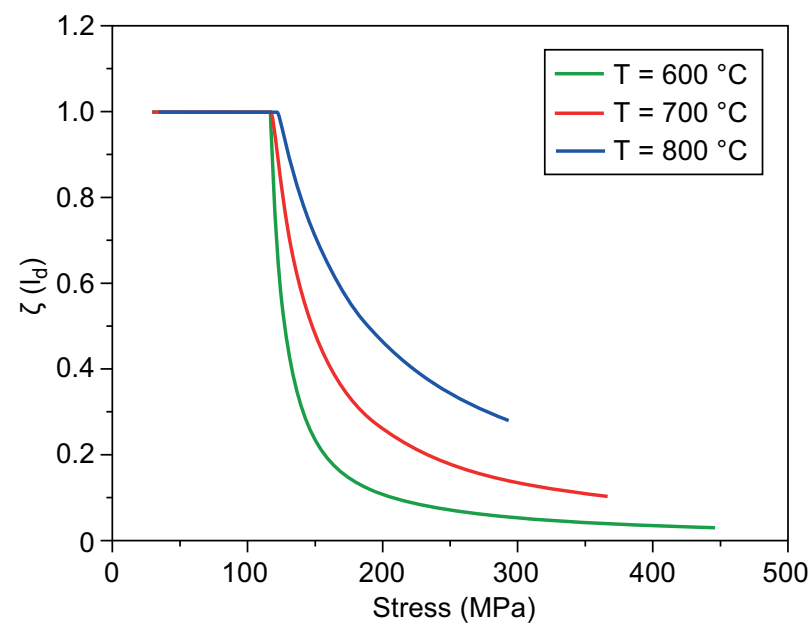

c)

\section{RESULTS AND DISCUSSION}

The effects of the pre-exposure temperature and time, interface shear stress, fibre strength and fibre Weibull modulus on the tensile damage process are analysed. The unidirectional $\mathrm{C} / \mathrm{SiC}$ composite is used for the case analysis, and the material properties are given by: $V_{\mathrm{f}}=40 \%, E_{\mathrm{f}}=230 \mathrm{GPa}, E_{\mathrm{m}}=350 \mathrm{GPa}, r_{\mathrm{f}}=3.5 \mu \mathrm{m}$, $m=6, \sigma_{R}=100 \mathrm{MPa}, 1_{\mathrm{sat}}=150 \mu \mathrm{m}, \alpha_{\mathrm{f}}=0 \times 10^{-6} \cdot \mathrm{K}^{-1}, \alpha_{\mathrm{m}}=$ $=4.6 \times 10^{-6} \cdot \mathrm{K}^{-1}, \Delta T=-1000^{\circ} \mathrm{C}, \zeta_{\mathrm{d}}=0.1 \mathrm{~J} \cdot \mathrm{m}^{-2}, \tau_{\mathrm{i}}=10 \mathrm{MPa}$, $\tau_{\mathrm{f}}=1 \mathrm{MPa}, \sigma_{\mathrm{c}}=1.6 \mathrm{GPa}$ and $m_{f}=5$.

The effect of the pre-exposure temperature on the tensile and damage process

The effect of the pre-exposure temperature (i.e., $T=600{ }^{\circ} \mathrm{C}, 700{ }^{\circ} \mathrm{C}$ and $800{ }^{\circ} \mathrm{C}$ ) on the tensile stressstrain curves, interface debonding and oxidation and the fibre failure of the $\mathrm{C} / \mathrm{SiC}$ composite corresponding to the pre-exposure time of $t=20 \mathrm{~h}$ is shown in Figure 2.

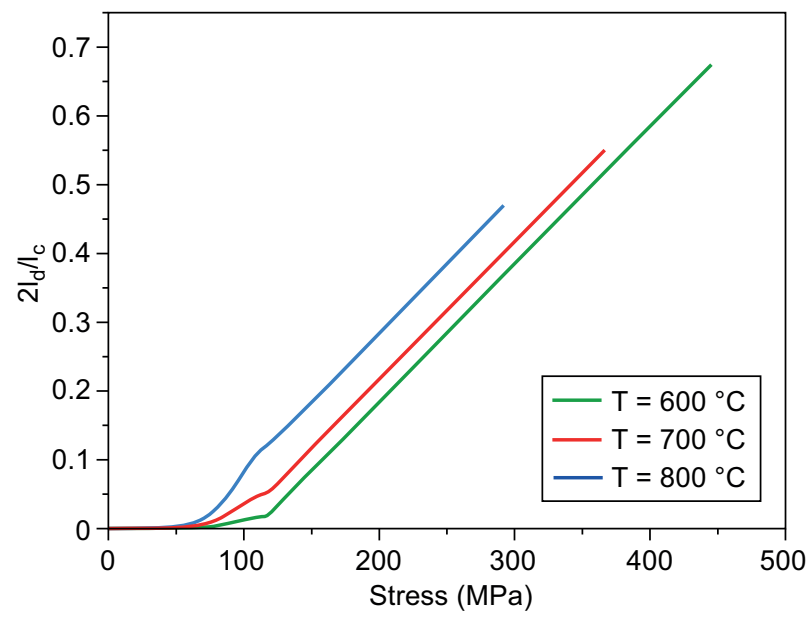

b)

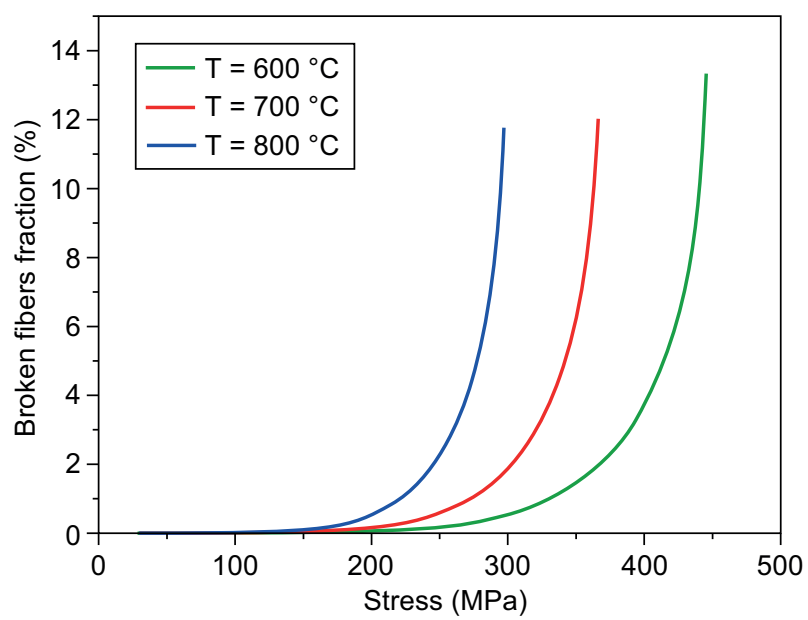

d)

Figure 2. The effect of the pre-exposure temperature on: a) the tensile stress-strain curves; b) the interface de-bonded length of $2 l_{\mathrm{d}} / l_{\mathrm{c}}$ versus the applied stress curves; c) the interface oxidation ratio of $\zeta / l_{\mathrm{d}}$ versus the applied stress curves; d) the broken fibre fraction versus the applied stress curves of the $\mathrm{C} / \mathrm{SiC}$ composite. 
When the pre-exposure temperature increases, the composite tensile strength and failure strain both decrease; the interface de-bonded length and the interface oxidation ratio both increase; and the fibre broken fraction increases at the low applied stress level.

When the pre-exposure temperature is $T=600{ }^{\circ} \mathrm{C}$, the composite tensile strength is $\sigma_{\mathrm{UTS}}=445 \mathrm{MPa}$ with the failure strain of $\varepsilon_{\mathrm{f}}=0.57 \%$; the interface debonded length increases to $2 l_{\mathrm{d}} / l_{\mathrm{c}}=67.5 \%$; the interface oxidation ratio decreases to $\zeta / l_{\mathrm{d}}=2.9 \%$; and the fibre broken fraction increases to $P=13.3 \%$.

When the pre-exposure temperature is $T=700{ }^{\circ} \mathrm{C}$, the composite tensile strength is $\sigma_{\mathrm{UTS}}=366 \mathrm{MPa}$ with the failure strain of $\varepsilon_{\mathrm{f}}=0.45 \%$; the interface de-bonded length increases to $2 l_{\mathrm{d}} / l_{\mathrm{c}}=55 \%$; the interface oxidation ratio decreases to $\zeta / l_{\mathrm{d}}=10.3 \%$; and the fibre broken fraction increases to $P=12.1 \%$.

When the pre-exposure temperature is $T=800{ }^{\circ} \mathrm{C}$, the composite tensile strength is $\sigma_{\mathrm{UTS}}=297 \mathrm{MPa}$ with the failure strain of $\varepsilon_{\mathrm{f}}=0.37 \%$; the interface de-bonded length increases to $2 l_{\mathrm{d}} / l_{\mathrm{c}}=48 \%$; the interface oxidation ratio decreases to $\zeta / l_{\mathrm{d}}=27.5 \%$; and the fibre broken fraction increases to $P=12 \%$.

The effect of the pre-exposure time on the tensile and damage processes

The effect of the pre-exposure time (i.e., $t=10,20$ and $30 \mathrm{~h}$ ) on the tensile stress-strain curves, interface debonding and oxidation and the fibre failure of the $\mathrm{C} / \mathrm{SiC}$ composite corresponding to the pre-exposure temperature of $T=800{ }^{\circ} \mathrm{C}$ is shown in Figure 3. When the pre-exposure time increases, the composite tensile strength and failure strain both decrease; the interface de-bonded length and the interface oxidation ratio both increase; and the fibre broken fraction increases at the low applied stress level.

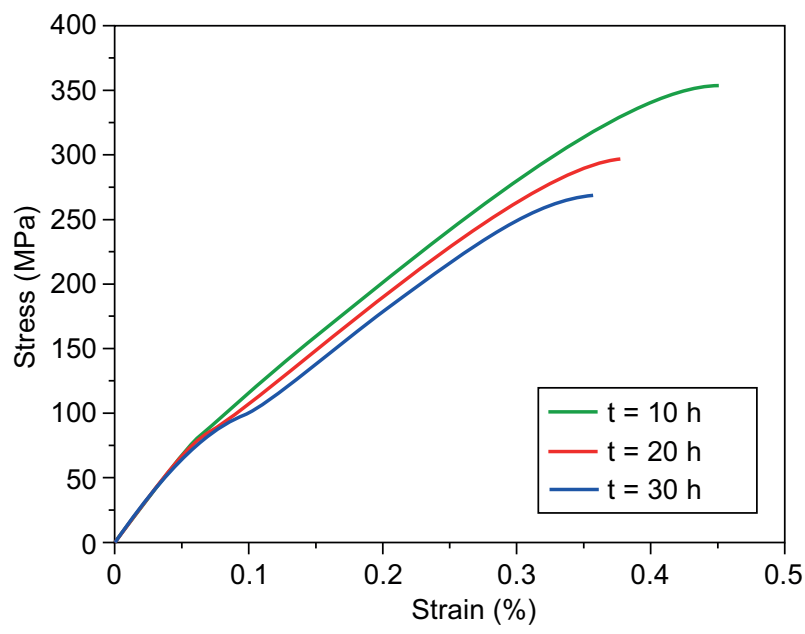

a)

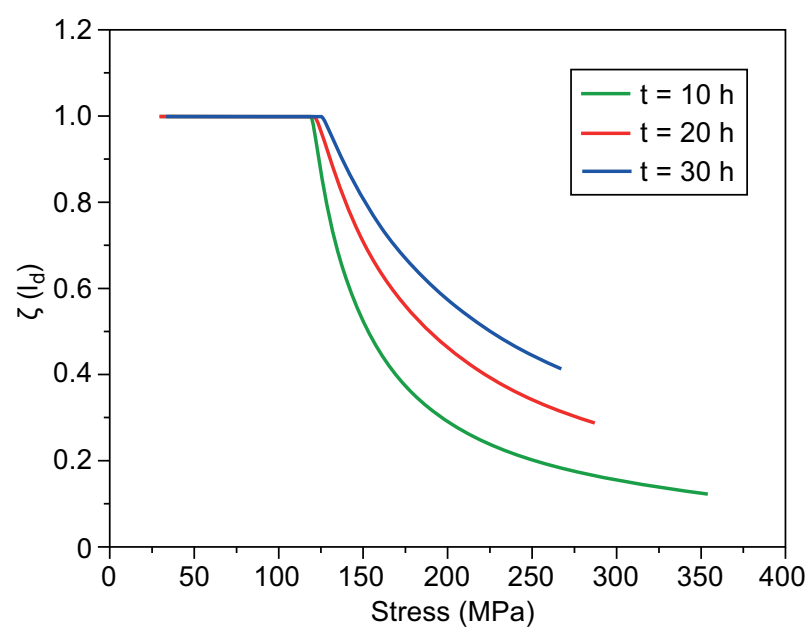

c)

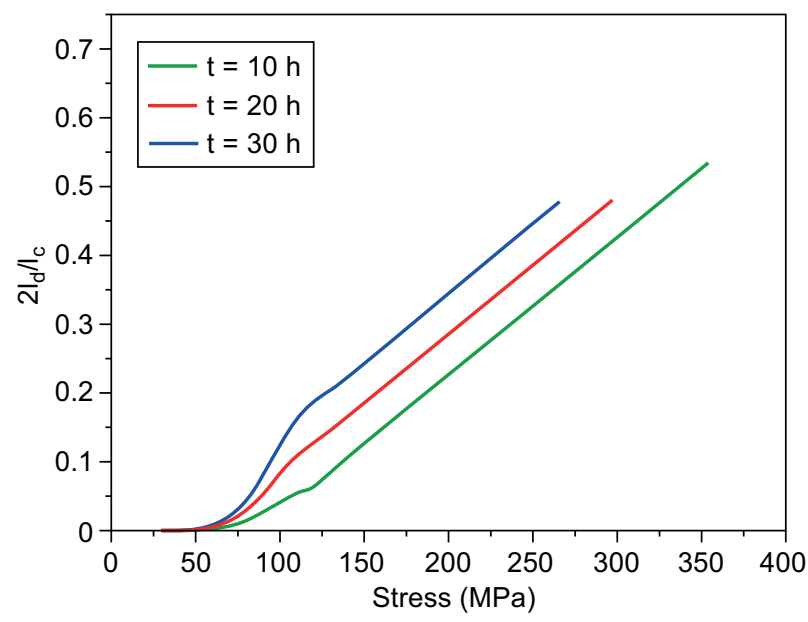

b)

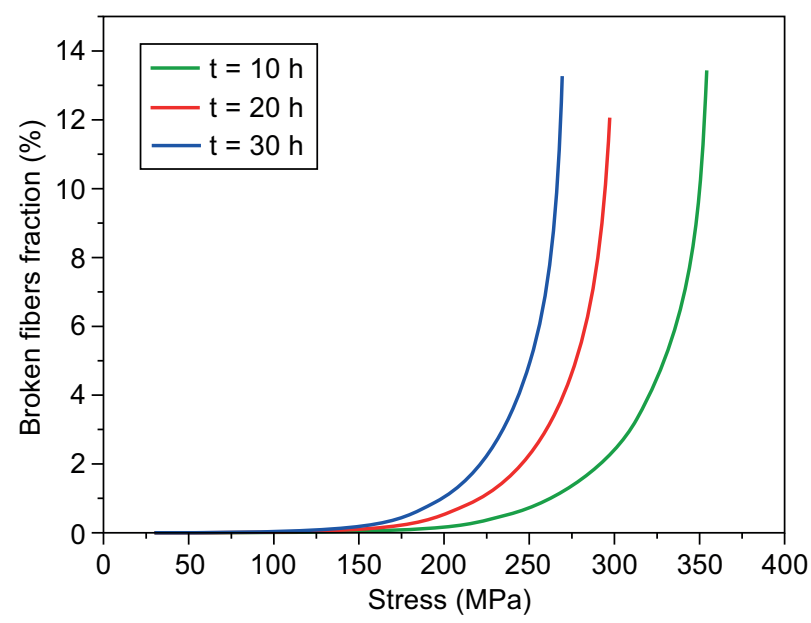

d)

Figure 3. The effect of the pre-exposure time on: a) the tensile stress-strain curves; b) the interface de-bonded length of $2 l_{\mathrm{d}} / l_{\mathrm{c}}$ versus the applied stress curves; c) the interface oxidation ratio of $\zeta / l_{\mathrm{d}}$ versus the applied stress curves; d) the broken fibre fraction versus the applied stress curves of the $\mathrm{C} / \mathrm{SiC}$ composite. 
When the pre-exposure time is $t=10 \mathrm{~h}$, the composite tensile strength is $\sigma_{\mathrm{UTS}}=354 \mathrm{MPa}$ with the failure strain of $\varepsilon_{\mathrm{f}}=0.45 \%$; the interface de-bonded length increases to $2 l_{\mathrm{d}} / l_{\mathrm{c}}=53 \%$; the interface oxidation ratio decreases to $\zeta / l_{\mathrm{d}}=12.3 \%$; and the fibre broken fraction increases to $P=13.4 \%$.

When the pre-exposure time is $t=20 \mathrm{~h}$, the composite tensile strength is $\sigma_{\mathrm{UTS}}=297 \mathrm{MPa}$ with the failure strain of $\varepsilon_{\mathrm{f}}=0.37 \%$; the interface de-bonded length increases to $2 l_{\mathrm{d}} / l_{\mathrm{c}}=48 \%$; the interface oxidation ratio decreases to $\zeta / l_{\mathrm{d}}=27.5 \%$; and the fibre broken fraction increases to $\mathrm{P}=12 \%$.

When the pre-exposure time is $t=30 \mathrm{~h}$, the composite tensile strength is $\sigma_{\mathrm{UTS}}=269 \mathrm{MPa}$ with the failure strain of $\varepsilon_{\mathrm{f}}=0.35 \%$; the interface de-bonded length increases to $2 l_{\mathrm{d}} / l_{\mathrm{c}}=48.4 \%$; the interface oxidation ratio decreases to $\zeta / l_{\mathrm{d}}=41 \%$; and the fibre broken fraction increases to $P=13.5 \%$.

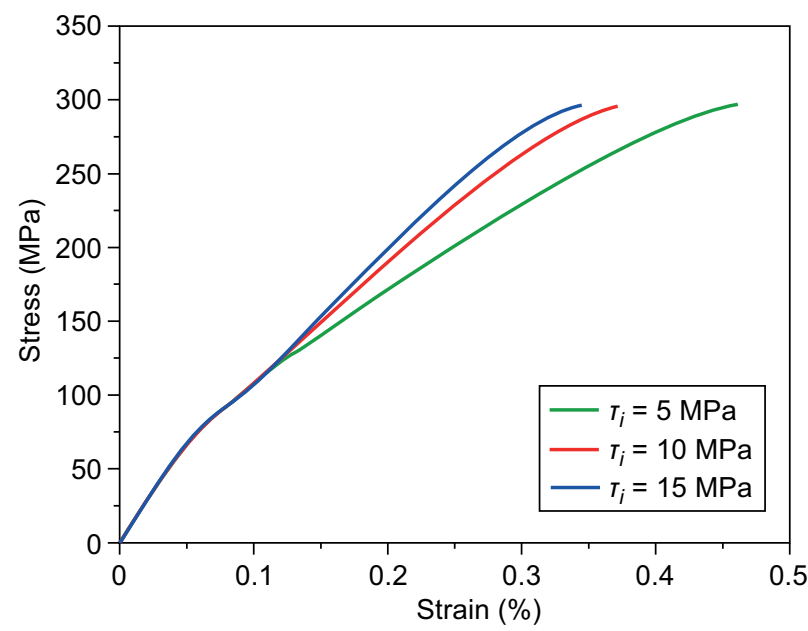

a)

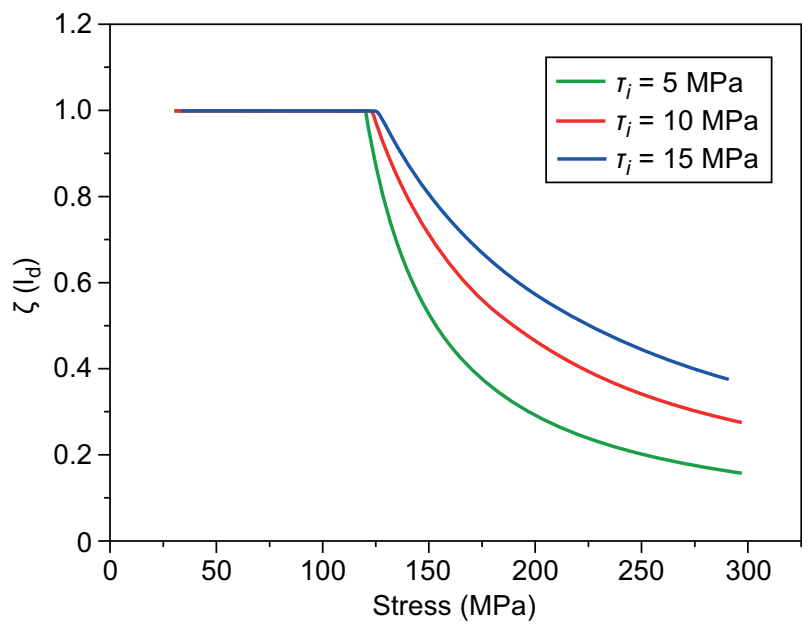

c)
The effect of the interface shear stress on the tensile and damage processes

The effect of the interface shear stress (i.e., $\tau_{\mathrm{i}}=5$, 10 and $15 \mathrm{MPa}$ ) on the tensile stress-strain curves, interface debonding and oxidation and the fibre failure of the $\mathrm{C} / \mathrm{SiC}$ composite corresponding to the pre-exposure temperature of $T=800^{\circ} \mathrm{C}$ and the pre-exposure time of $t=20 \mathrm{~h}$ is shown in Figure 4. When the interface shear stress increases, the composite failure strain decreases; the interface de-bonded length decreases, and the interface oxidation ratio increases.

When the interface shear stress is $\tau_{\mathrm{i}}=5 \mathrm{MPa}$, the composite failure strain is $\varepsilon_{\mathrm{f}}=0.46 \%$; the interface debonded length increases to $2 l_{\mathrm{d}} / l_{\mathrm{c}}=84 \%$; the interface oxidation ratio decreases to $\zeta / l_{\mathrm{d}}=15.7 \%$; and the fibre broken fraction increases to $P=12 \%$.

When the interface shear stress is $\tau_{\mathrm{i}}=10 \mathrm{MPa}$, the composite failure strain is $\varepsilon_{\mathrm{f}}=0.37 \%$; the interface

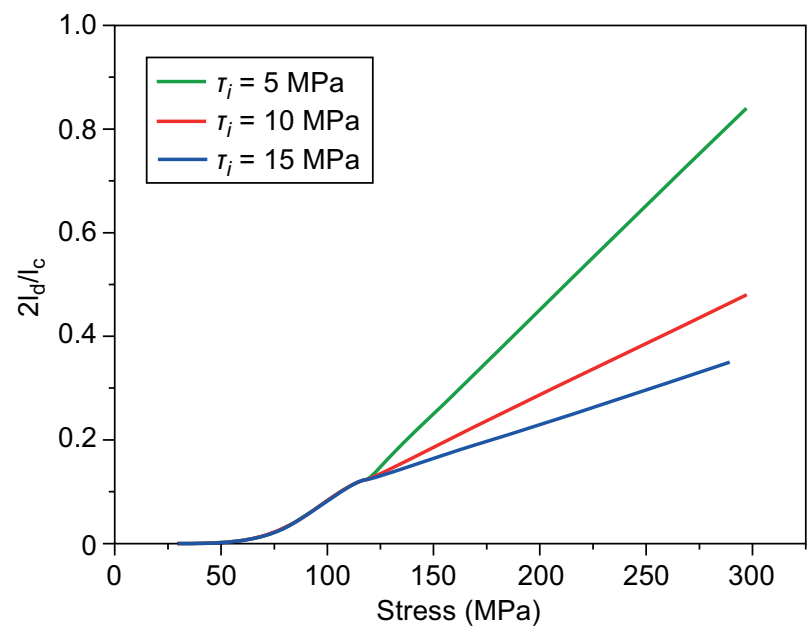

b)

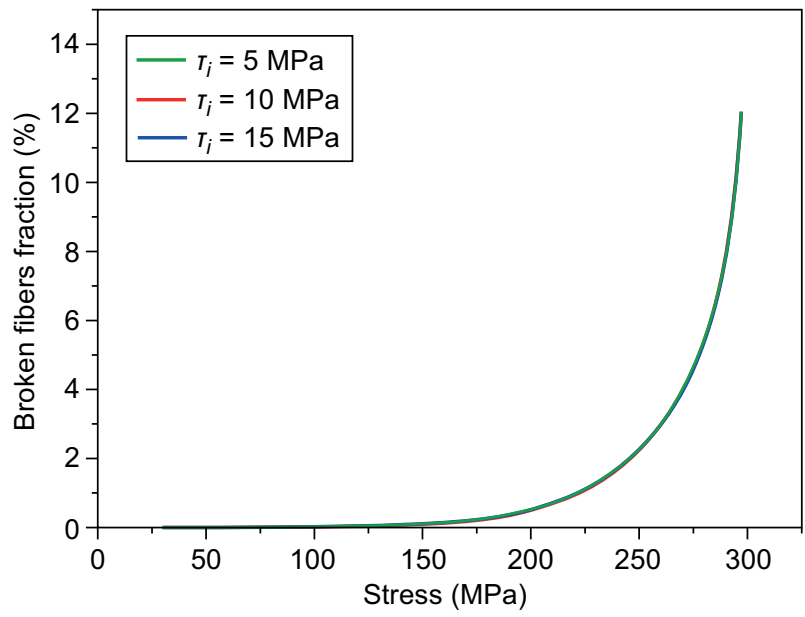

d)

Figure 4. The effect of the interface shear stress on: a) the tensile stress-strain curves; b) the interface de-bonded length of $2 l_{d} / l_{c}$ versus the applied stress curves; c) the interface oxidation ratio of $\zeta / l_{\mathrm{d}}$ versus the applied stress curves; d) the broken fibre fraction versus the applied stress curves of the $\mathrm{C} / \mathrm{SiC}$ composite. 
de-bonded length increases to $2 l_{\mathrm{d}} / l_{\mathrm{c}}=48 \%$; the interface oxidation ratio decreases to $\zeta / l_{\mathrm{d}}=27 \%$; and the fibre broken fraction increases to $P=12 \%$.

When the interface shear stress is $\tau_{\mathrm{i}}=15 \mathrm{MPa}$, the composite failure strain is $\varepsilon_{\mathrm{f}}=0.35 \%$; the interface debonded length increases to $2 l_{\mathrm{d}} l_{\mathrm{c}}=36 \%$; the interface oxidation ratio decreases to $\zeta / l_{\mathrm{d}}=36.7 \%$; and the fibre broken fraction increases to $P=12 \%$.

The effect of the fibre strength on the tensile and damage processes

The effect of the fibre strength (i.e., $\sigma_{\mathrm{o}}=1$ and $2 \mathrm{GPa}$ ) on the tensile stress-strain curves and the fibre failure of the $\mathrm{C} / \mathrm{SiC}$ composite corresponding to the pre-exposure temperature of $T=800{ }^{\circ} \mathrm{C}$ and the preexposure time of $t=20 \mathrm{~h}$ is shown in Figure 5. When the fibre strength increases, the composite tensile strength and failure strain both increase; and the fibre broken fraction decreases at the low applied stress level.

When the fibre strength is $\sigma_{\mathrm{o}}=1 \mathrm{GPa}$, the composite tensile strength is $\sigma_{\mathrm{UTS}}=278 \mathrm{MPa}$ with the failure strain of $\varepsilon_{\mathrm{f}}=0.31 \%$; and the fibre broken fraction increases to $P=12.9 \%$.

When the fibre strength is $\sigma_{0}=2 \mathrm{GPa}$, the composite tensile strength is $\sigma_{\mathrm{UTS}}=354 \mathrm{MPa}$ with the failure strain of $\varepsilon_{\mathrm{f}}=0.41 \%$; and the fibre broken fraction increases to $P=13.4 \%$.

The effect of the fibre Weibull modulus on the tensile and damage processes

The effect of the fibre Weibull modulus (i.e., $m_{\mathrm{f}}=3$ and 5) on the tensile stress-strain curves and the fibre failure of the $\mathrm{C} / \mathrm{SiC}$ composite corresponding to the pre-exposure temperature of $T=800{ }^{\circ} \mathrm{C}$ and the

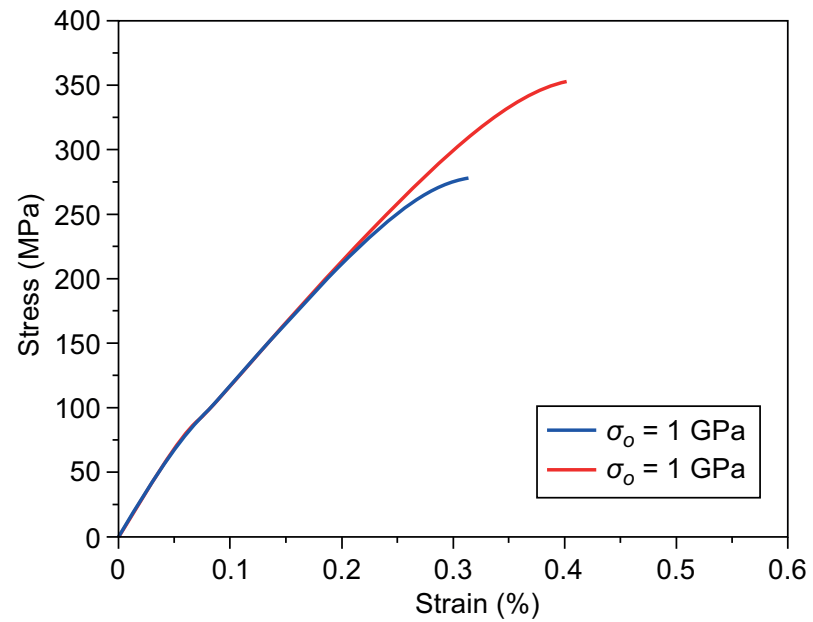

a)

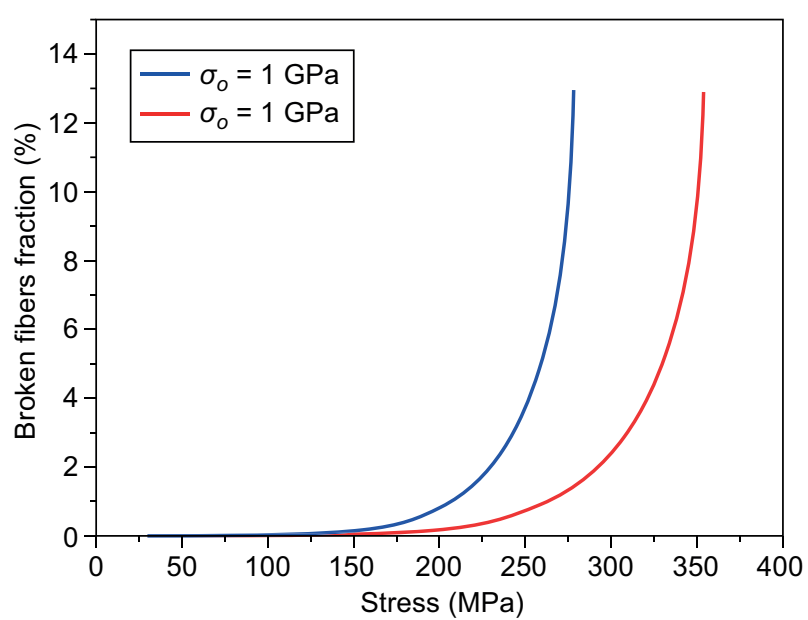

b)

Figure 5. The effect of the fibre strength on: a) the tensile stress-strain curves; b) the broken fibre fraction versus the applied stress curves of the $\mathrm{C} / \mathrm{SiC}$ composite.

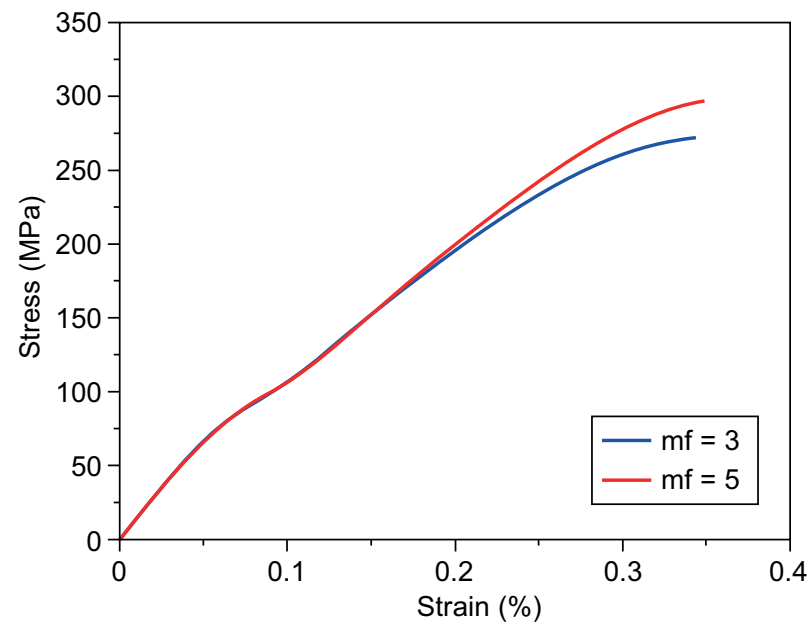

a)

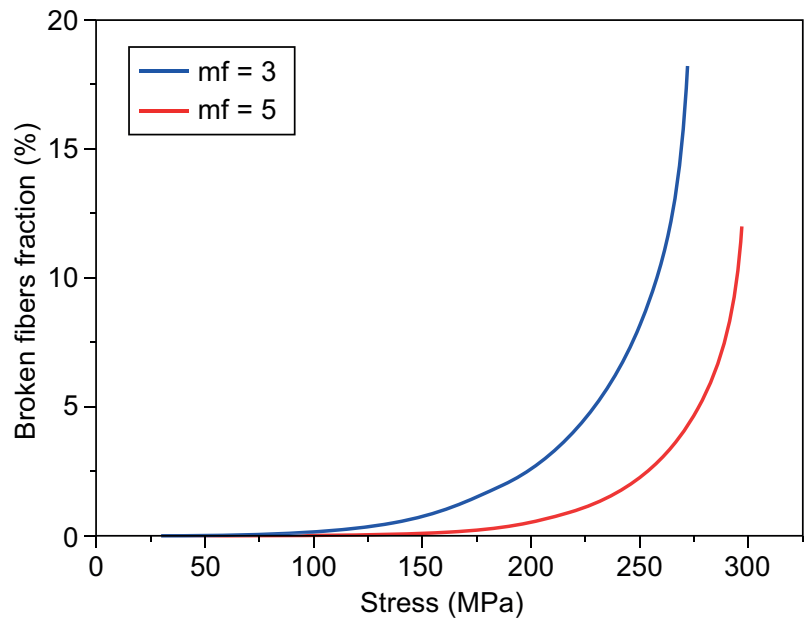

b)

Figure 6. The effect of the fibre Weibull modulus on: a) the tensile stress-strain curves; $b$ ) the broken fibre fraction versus the applied stress curves of the $\mathrm{C} / \mathrm{SiC}$ composite. 
pre-exposure time of $t=20 \mathrm{~h}$ is shown in Figure 6. When the fibre Weibull modulus increases, the composite tensile strength and failure strain both increase; and the fibre broken fraction decreases at the low applied stress level.

When the fibre Weibull modulus is $m_{\mathrm{f}}=3$, the composite tensile strength is $\sigma_{\mathrm{UTS}}=272 \mathrm{MPa}$ with the failure strain of $\varepsilon_{\mathrm{f}}=0.34 \%$; and the fibre broken fraction increases to $P=18.2 \%$.

When the fibre Weibull modulus is $m_{\mathrm{f}}=5$, the composite tensile strength is $\sigma_{\mathrm{UTS}}=297 \mathrm{MPa}$ with the failure strain of $\varepsilon_{\mathrm{f}}=0.35 \%$; and the fibre broken fraction increases to $P=12 \%$.

\section{EXPERIMENTAL}

Wang et al. [8] investigated the tensile behaviour of $1 \mathrm{D}, 2 \mathrm{D}$ and $3 \mathrm{D} \mathrm{C} / \mathrm{SiC}$ composites at room temperature. Zhang et al. [9] investigated the tensile behaviour of 2.5D $\mathrm{C} / \mathrm{SiC}$ composites after exposure at an elevated

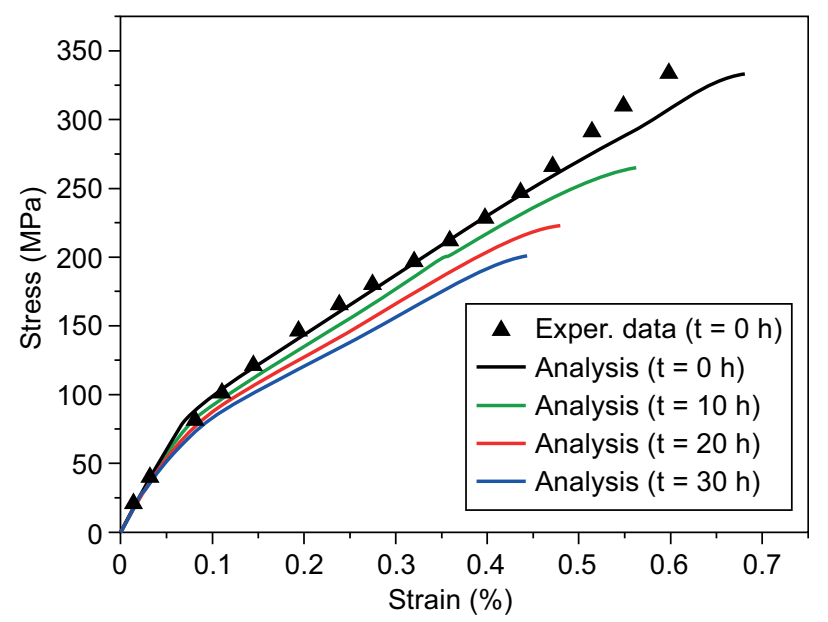

a)

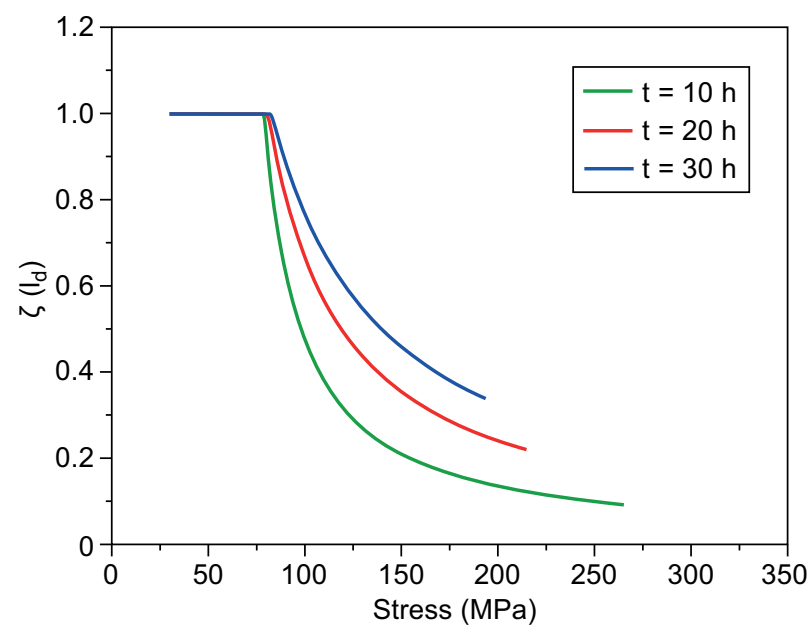

c) temperature. The material properties of the $1 \mathrm{D}, 2 \mathrm{D}$, 2.5D and $3 \mathrm{D} \mathrm{C} / \mathrm{SiC}$ composites are listed in Table 1.

Table 1. The material properties of the $\mathrm{C} / \mathrm{SiC}$ composites.

\begin{tabular}{ccccc}
\hline Items & $1 \mathrm{D} \mathrm{C} / \mathrm{SiC}$ & $2 \mathrm{D} \mathrm{C} / \mathrm{SiC}$ & $2.5 \mathrm{D} \mathrm{C} / \mathrm{SiC}$ & $3 \mathrm{D} \mathrm{C} / \mathrm{SiC}$ \\
\hline$\lambda$ & 1 & 0.5 & 0.75 & 0.93 \\
$r_{\mathrm{f}}(\mu \mathrm{m})$ & 3.5 & 3.5 & 3.5 & 3.5 \\
$V_{\mathrm{f}}(\%)$ & 30 & 35 & 40 & 40 \\
$E_{\mathrm{f}}(\mathrm{GPa})$ & 230 & 230 & 230 & 230 \\
$\alpha_{\mathrm{f}}\left(10^{-6} \cdot \mathrm{K}^{-1}\right)$ & 0 & 0 & 0.5 & 0 \\
$\alpha_{\mathrm{m}}\left(10^{-6} \cdot \mathrm{K}^{-1}\right)$ & 4.6 & 4.6 & 4.6 & 4.6 \\
$m$ & 3 & 5 & 6 & 5 \\
$\sigma_{\mathrm{R}}(\mathrm{MPa})$ & 100 & 40 & 80 & 80 \\
$l_{\text {sat }}(\mu \mathrm{m})$ & 120 & 300 & 80 & 80 \\
$\tau_{\mathrm{i}}(\mathrm{MPa})$ & 10 & 11 & 5 & 9 \\
$\tau_{\mathrm{f}}(\mathrm{MPa})$ & 1 & 1 & 1 & 1 \\
$\zeta_{\mathrm{d}}\left(\mathrm{J} \cdot \mathrm{m}^{-2}\right)$ & 0.1 & 0.3 & 0.1 & 0.1 \\
$\sigma_{\mathrm{UTS}}(\mathrm{MPa})$ & 333 & 149 & 226 & 206 \\
$\varepsilon_{\mathrm{f}}(\%)$ & 0.59 & 0.34 & 0.56 & 0.37 \\
$m_{\mathrm{f}}$ & 5 & 5 & 5 & 5 \\
\hline
\end{tabular}

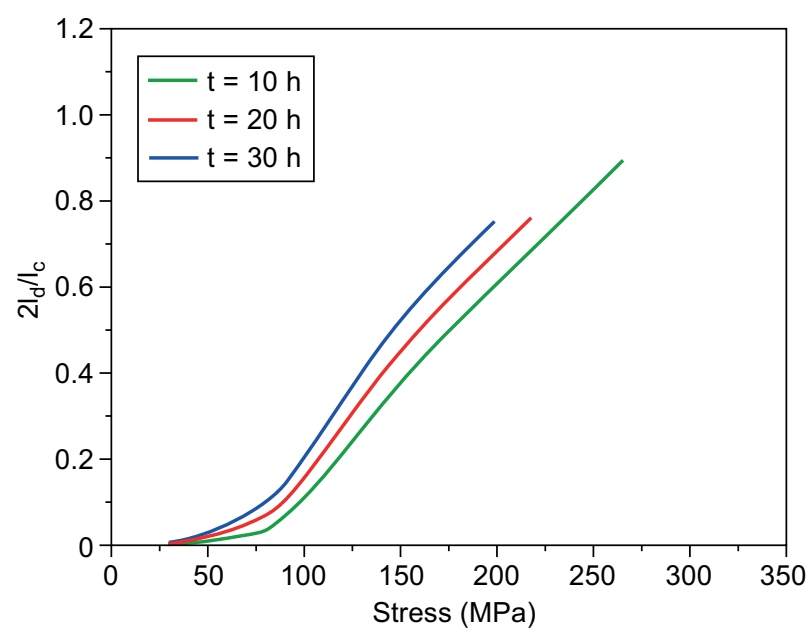

b)

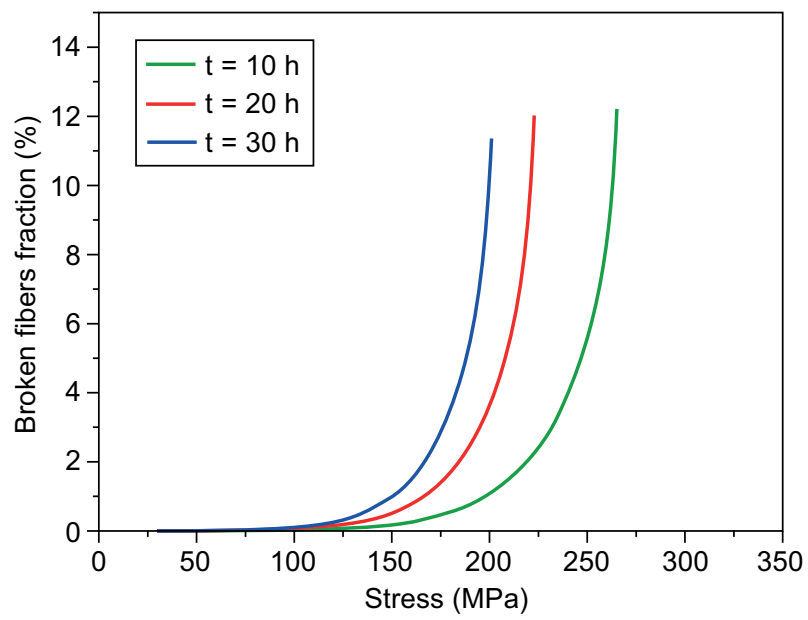

d)

Figure 7. a) The experimental and predicted tensile stress-strain curves; b) the interface de-bonded length of $2 l_{\mathrm{d}} / l_{\mathrm{c}}$ versus the applied stress curves; c) the interface oxidation ratio of $\zeta / l_{\mathrm{d}}$ versus the applied stress curves; $d$ ) the broken fibre fraction versus the applied stress curves of the unidirectional $\mathrm{C} / \mathrm{SiC}$ composite. 
The experimental and predicted tensile stressstrain curves, interface de-bonded length and oxidation length, and the fibre broken fraction of the $1 \mathrm{D} \mathrm{C} / \mathrm{SiC}$ composite without and with the pre-exposure at $T=$ $=800{ }^{\circ} \mathrm{C}$ and $t=10,20$ and $30 \mathrm{~h}$ are shown in Figure 7. With the increasing pre-exposure time, the composite tensile strength and failure strain both decrease; the interface de-bodned length and interface oxidation ratio increase; and the broken fibres fraction increases at the low stress level. Without the pre-exposure, the composite tensile strength is $\sigma_{\mathrm{UTS}}=333 \mathrm{MPa}$ with the failure strain of $\varepsilon_{\mathrm{f}}=0.68 \%$; when the pre-exposure time is $t=10 \mathrm{~h}$, the composite tensile strength is $\sigma_{\mathrm{UTS}}=314 \mathrm{MPa}$ with the failure strain of $\varepsilon_{\mathrm{f}}=0.67 \%$, the interface de-bonded length increases to $2 l_{\mathrm{d}} / l_{\mathrm{c}}=1$, the interface oxidation ratio decreases to $\zeta / l_{\mathrm{d}}=24.8 \%$, and the broken fibres fraction increases to $P=12 \%$; when the pre-exposure time is $t=20 \mathrm{~h}$, the composite tensile strength is $\sigma_{\mathrm{UTS}}=$ $=264 \mathrm{MPa}$ with the failure strain of $\varepsilon_{\mathrm{f}}=0.61 \%$, the interface de-bonded length increases to $2 l_{\mathrm{d}} / l_{\mathrm{c}}=1$, the interface oxidation ratio decreases to $\zeta / l_{\mathrm{d}}=49 \%$, and the broken fibres fraction increases to $P=12 \%$; when the pre-exposure time is $t=30 \mathrm{~h}$, the composite tensile strength is $\sigma_{\mathrm{UTS}}=239 \mathrm{MPa}$ with the failure strain of $\varepsilon_{\mathrm{f}}=0.59 \%$, the interface de-bonded length increases to $2 l_{\mathrm{d}} / l_{\mathrm{c}}=1$, the interface oxidation ratio decreases to $\zeta / l_{\mathrm{d}}=$ $=74.4 \%$, and the broken fibres fraction increases to $P=12.8 \%$.

The experimental and predicted tensile stressstrain curves, interface de-bonded length and oxidation length, and the fibre broken fraction of the $2 \mathrm{D} \mathrm{C} / \mathrm{SiC}$ composite without and with the pre-exposure at $T=$ $800^{\circ} \mathrm{C}$ and $t=10,20$ and $30 \mathrm{~h}$ are shown in Figure 8. With the increasing pre-exposure time, the composite tensile strength and failure strain both decrease; the interface de-bodned length and interface oxidation ratio increase; and the broken fibres fraction increases at the low stress level. Without the pre-exposure, the

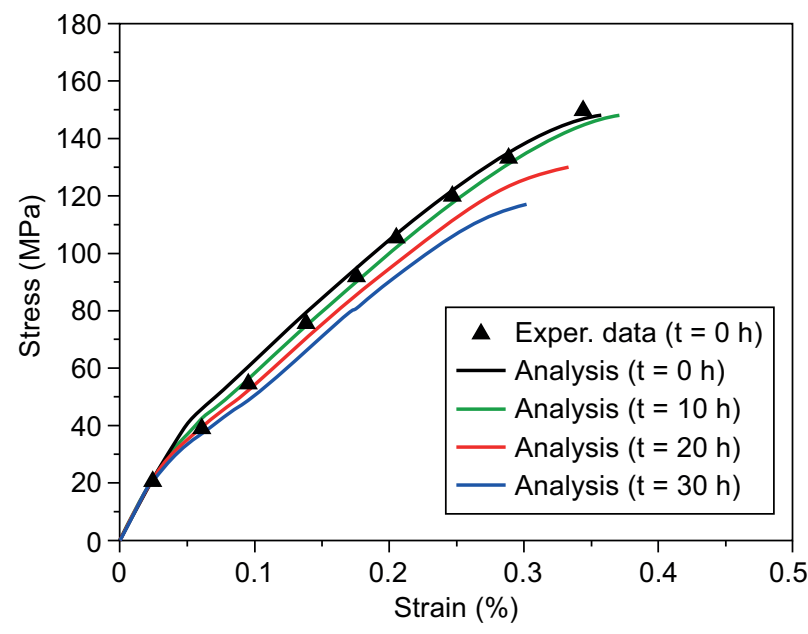

a)

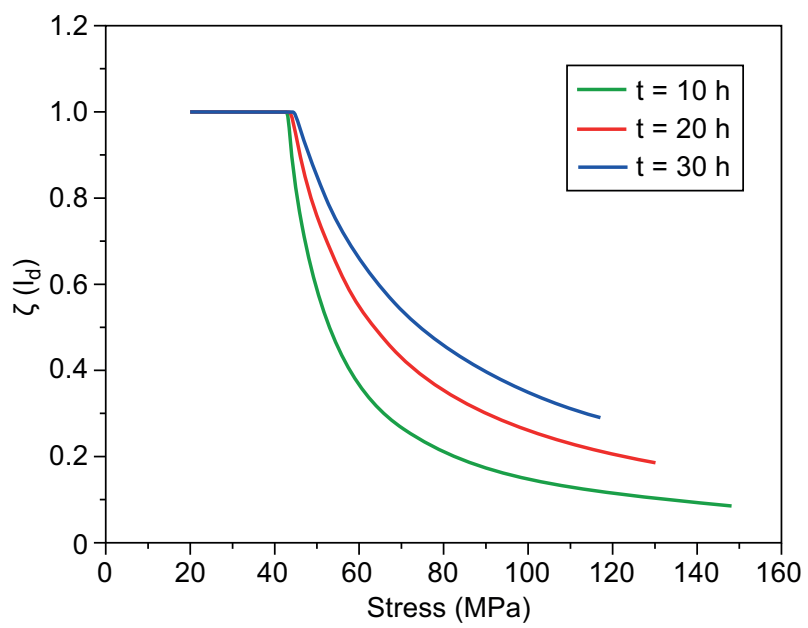

c)

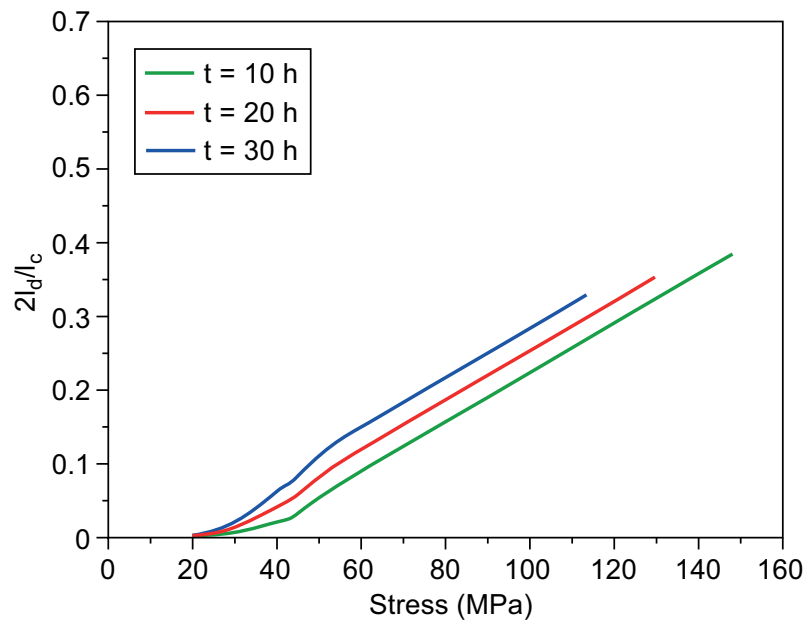

b)

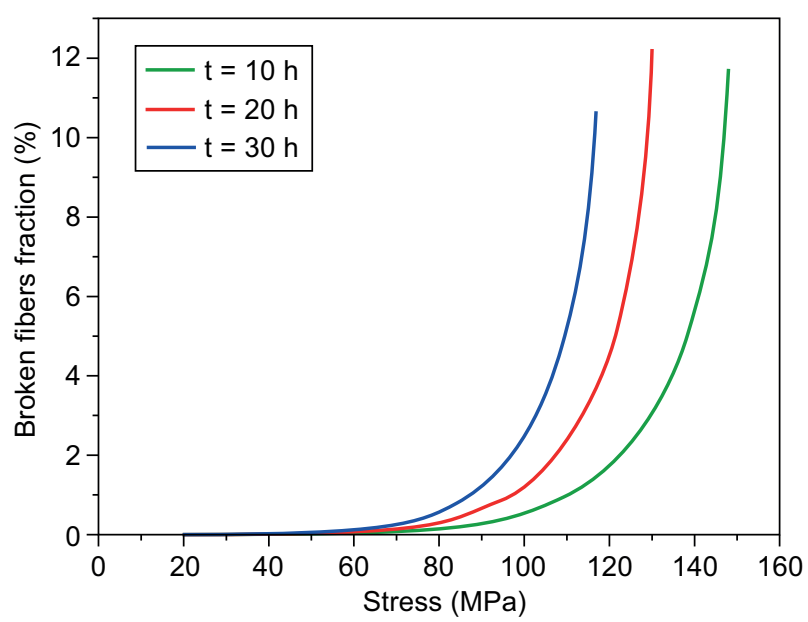

d)

Figure 8. a) The experimental and predicted tensile stress-strain curves; b) the interface de-bonded length of $2 l_{\mathrm{d}} / l_{\mathrm{c}}$ versus the applied stress curves; c) the interface oxidation ratio of $\zeta / l_{\mathrm{d}}$ versus the applied stress curves; $d$ ) the broken fibre fraction versus the applied stress curves of the $2 \mathrm{D} \mathrm{C} / \mathrm{SiC}$ composite. 
composite tensile strength is $\sigma_{\text {UTS }}=148 \mathrm{MPa}$ with the failure strain of $\varepsilon_{\mathrm{f}}=0.35 \%$; when the pre-exposure time is $t=10 \mathrm{~h}$, the composite tensile strength is $\sigma_{\mathrm{UTS}}=148 \mathrm{MPa}$ with the failure strain of $\varepsilon_{\mathrm{f}}=0.37 \%$, the interface de-bonded length increases to $2 l_{\mathrm{d}} / l_{\mathrm{c}}=38.4 \%$, the interface oxidation ratio decreases to $\zeta / l_{\mathrm{d}}=8.6 \%$, and the broken fibres fraction increases to $P=11.7 \%$; when the pre-exposure time is $t=20 \mathrm{~h}$, the composite tensile strength is $\sigma_{\mathrm{UTS}}=130 \mathrm{MPa}$ with the failure strain of $\varepsilon_{\mathrm{f}}=0.33 \%$, the interface de-bonded length increases to $2 l_{\mathrm{d}} / l_{\mathrm{c}}=35.4 \%$, the interface oxidation ratio decreases to $\zeta / l_{\mathrm{d}}=18.6 \%$, and the broken fibres fraction increases to $P=12.2 \%$; when the pre-exposure time is $t=30 \mathrm{~h}$, the composite tensile strength is $\sigma_{\mathrm{UTS}}=117 \mathrm{MPa}$ with the failure strain of $\varepsilon_{\mathrm{f}}=0.3 \%$, the interface de-bonded length increases to $2 l_{\mathrm{d}} / l_{\mathrm{c}}=34 \%$, the interface oxidation ratio decreases to $\zeta / l_{\mathrm{d}}=29 \%$, and the broken fibres fraction increases to $P=10.9 \%$.

The experimental and predicted tensile stress-strain curves, interface de-bonded length and oxidation length,

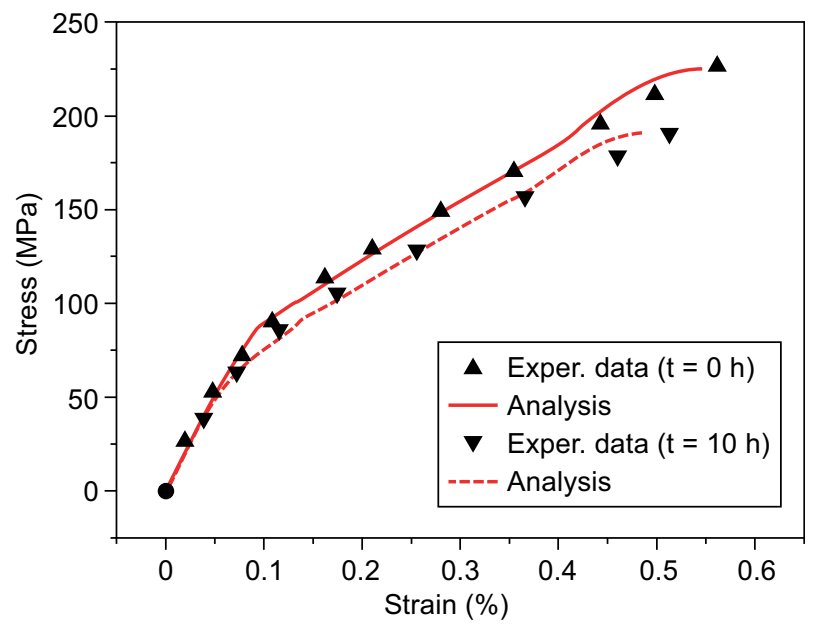

a)

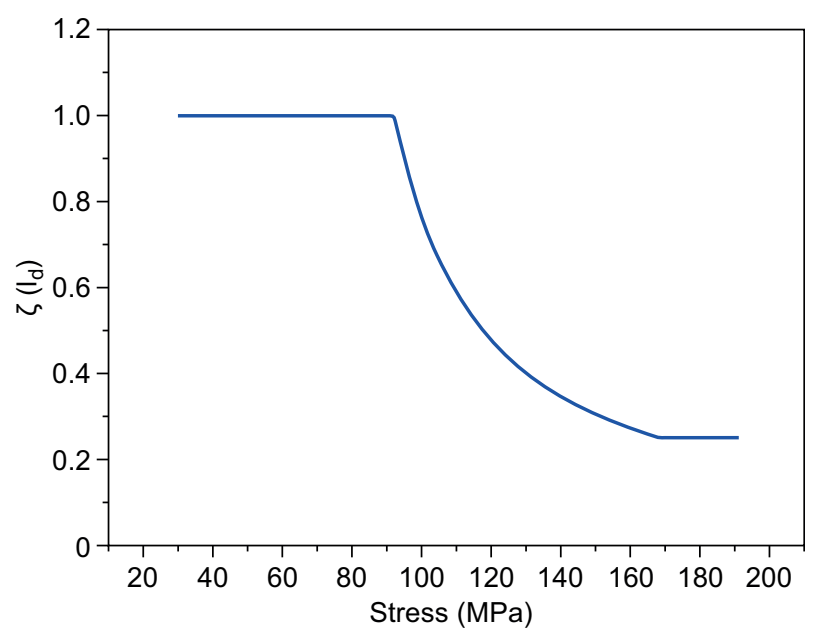

c) and fibre broken fraction of the $2.5 \mathrm{D} \mathrm{C} / \mathrm{SiC}$ composite without and with the pre-exposure at $T=900{ }^{\circ} \mathrm{C}$ and $t=10 \mathrm{~h}$ are shown in Figure 9. Without the pre-exposure, the composite tensile strength is $\sigma_{\mathrm{UTS}}=225 \mathrm{MPa}$ with the failure strain of $\varepsilon_{\mathrm{f}}=0.54 \%$; when the pre-exposure time is $t=10 \mathrm{~h}$, the composite tensile strength is $\sigma_{\mathrm{UTS}}=191 \mathrm{MPa}$ with the failure strain of $\varepsilon_{\mathrm{f}}=0.48 \%$, the interface de-bonded length increases to $2 l_{\mathrm{d}} / l_{\mathrm{c}}=1$, the interface oxidation ratio decreases to $\zeta / l_{\mathrm{d}}=25 \%$, and the broken fibres fraction increases to $P=23.5 \%$.

The experimental and predicted tensile stress-strain curves, interface de-bonded length and oxidation length, and the fibre broken fraction of the $3 \mathrm{D} \mathrm{C} / \mathrm{SiC}$ composite without and with the pre-exposure at $T=800{ }^{\circ} \mathrm{C}$ and $t=10,20$ and $30 \mathrm{~h}$ are shown in Figure 10. With the increasing pre-exposure time, the composite tensile strength and failure strain both decrease; the interface de-bodned length and interface oxidation ratio increase; and the broken fibres fraction increases at the low stress level. Without the pre-exposure, the composite tensile

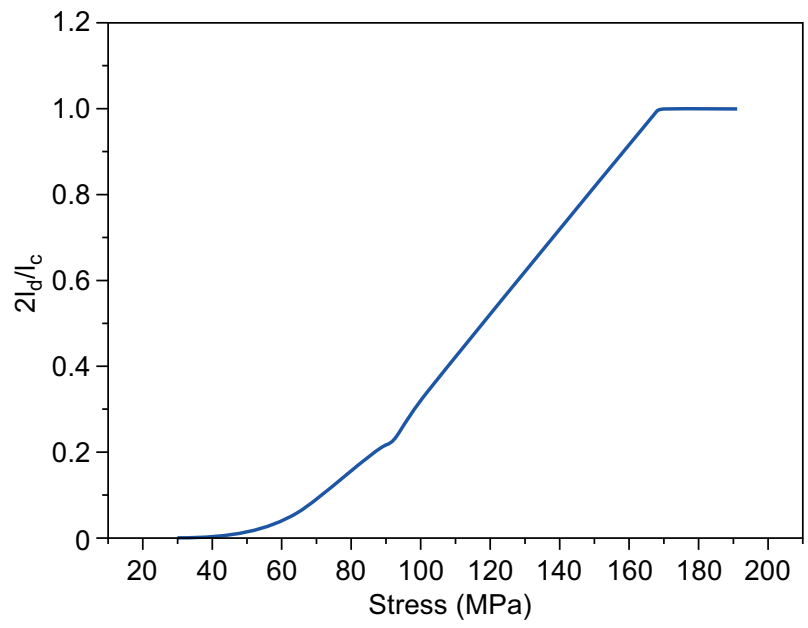

b)

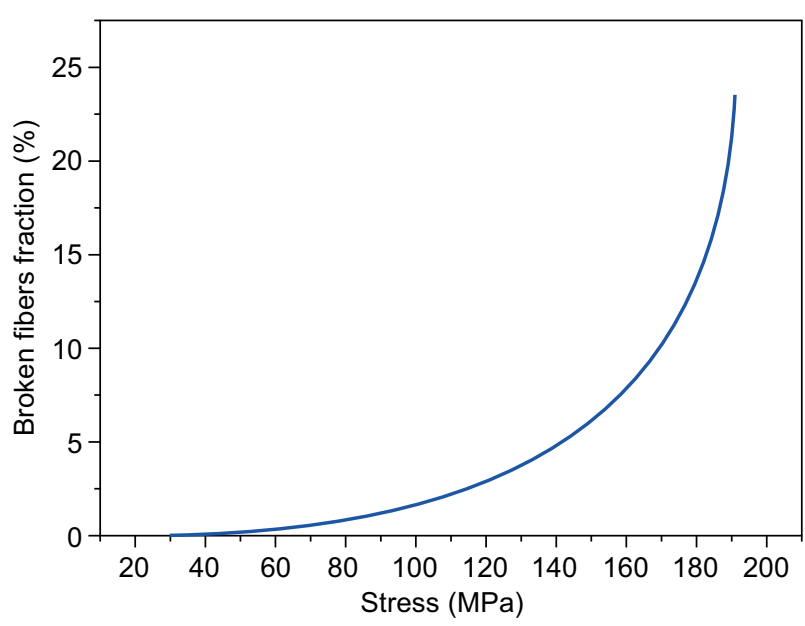

d)

Figure 9. a) The experimental and predicted tensile stress-strain curves; b) the interface de-bonded length of $2 l_{\mathrm{d}} / l_{\mathrm{c}}$ versus the applied stress curves; c) the interface oxidation ratio of $\zeta / l_{\mathrm{d}}$ versus the applied stress curves; $d$ ) the broken fibre fraction versus the applied stress curves of the $2.5 \mathrm{D} \mathrm{C} / \mathrm{SiC}$ composite. 
strength is $\sigma_{\text {UTS }}=203 \mathrm{MPa}$ with the failure strain of $\varepsilon_{\mathrm{f}}=0.38 \%$; when the pre-exposure time is $\mathrm{t}=10 \mathrm{~h}$, the composite tensile strength is $\sigma_{\mathrm{UTS}}=192 \mathrm{MPa}$ with the failure strain of $\varepsilon_{\mathrm{f}}=0.38 \%$, the interface de-bonded length increases to $2 l_{\mathrm{d}} / l_{\mathrm{c}}=83 \%$, the interface oxidation ratio decreases to $\zeta / l_{\mathrm{d}}=15 \%$, and the broken fibres fraction increases to $P=13.1 \%$; when the pre-exposure time is $t=20 \mathrm{~h}$, the composite tensile strength is $\sigma_{\text {UTS }}=161 \mathrm{MPa}$ with the failure strain of $\varepsilon_{\mathrm{f}}=0.33 \%$, the interface de-bonded length increases to $2 l_{\mathrm{d}} / l_{\mathrm{c}}=79 \%$, the interface oxidation ratio decreases to $\zeta / l_{\mathrm{d}}=31 \%$, and the broken fibres fraction increases to $P=11.7 \%$; when the pre-exposure time is $t=30 \mathrm{~h}$, the composite tensile strength is $\sigma_{\mathrm{UTS}}=145 \mathrm{MPa}$ with the failure strain of $\varepsilon_{\mathrm{f}}=0.32 \%$, the interface de-bonded length increases to $2 l_{\mathrm{d}} / l_{\mathrm{c}}=83 \%$, the interface oxidation ratio decreases to $\zeta / l_{\mathrm{d}}=44 \%$, and the broken fibres fraction increases to $P=10.8 \%$.

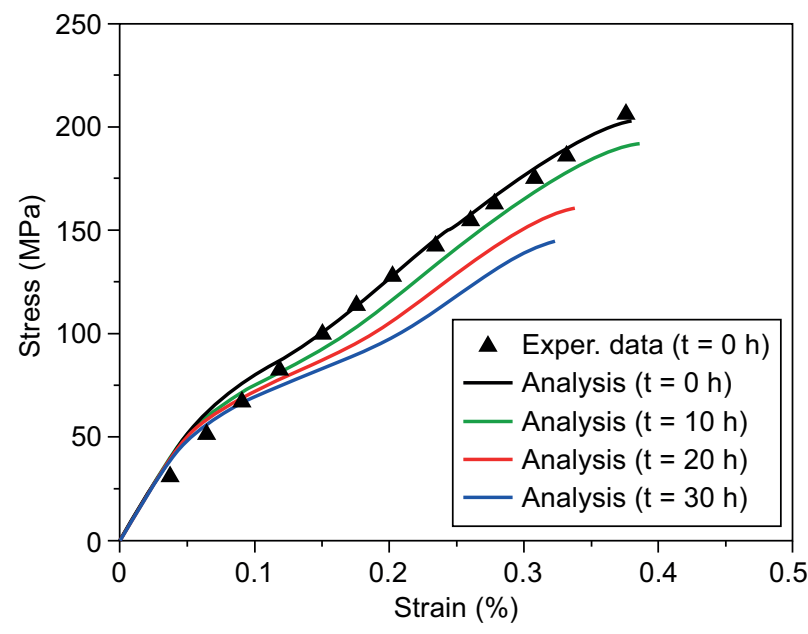

a)

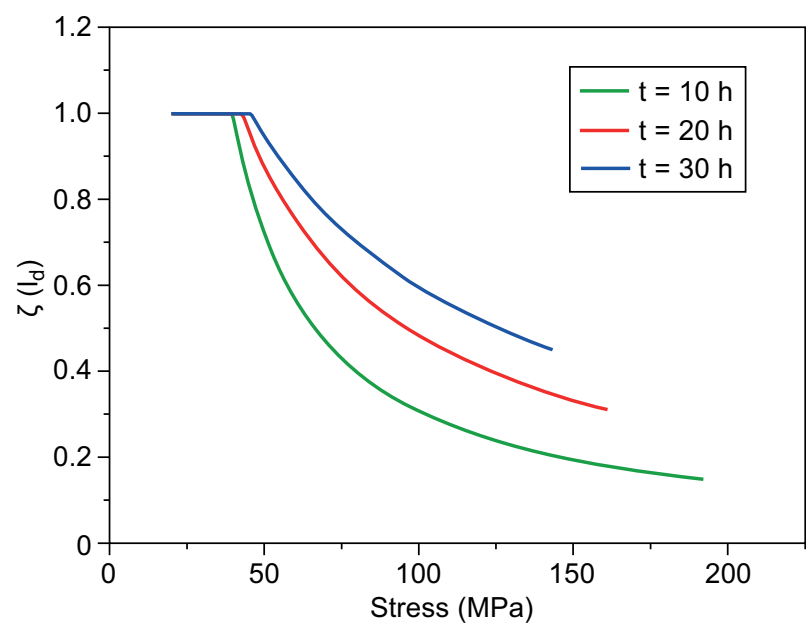

c)

\section{CONCLUSIONS}

In this paper, the tensile damage and fracture process of the fibre-reinforced CMCs under the effect of pre-exposure at elevated temperatures are investigated. The damage mechanisms of the interface oxidation and fibre failure are considered in the stress analysis, matrix multi-cracking, interface debonding and fibre failure. Combining the stress analysis and damage models, the tensile stress-strain curves of the fibre-reinforced CMCs for the different damage stages can be obtained. The effects of the pre-exposure temperatures and time, interface shear stress, fibre strength and fibre Weibull modulus on the tensile damage and fracture processes are analysed. The experimental tensile damage and fracture process of the fibre-reinforced CMCs with the different fibre preforms are predicted for the different pre-exposure temperatures and times.

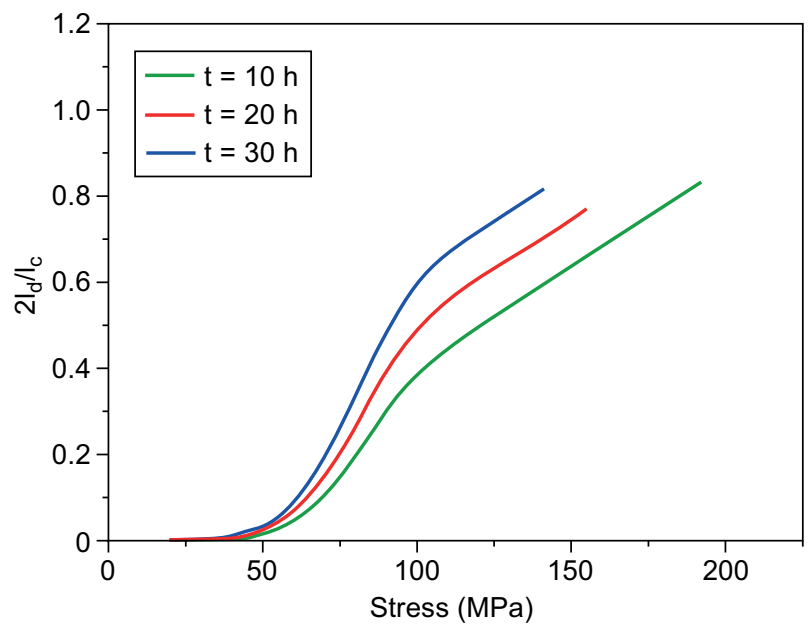

b)

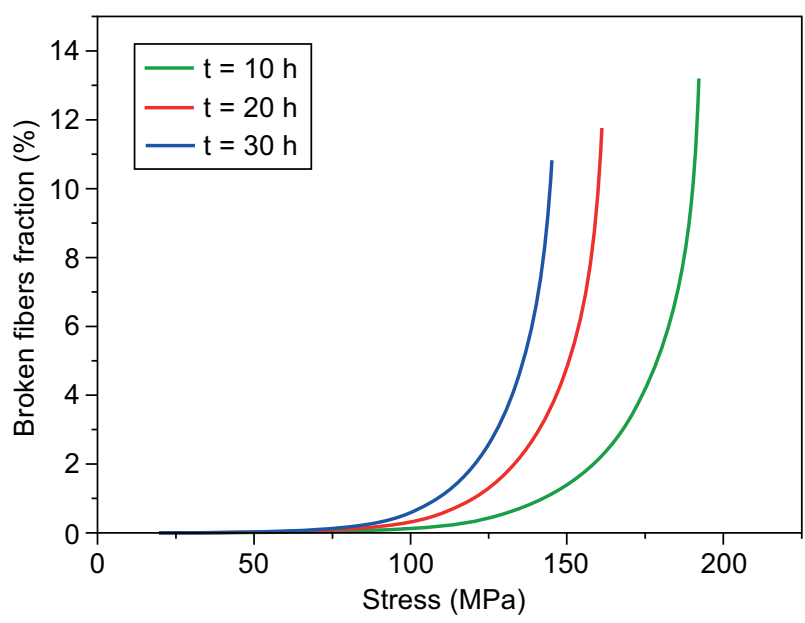

d)

Figure 10. a) The experimental and predicted tensile stress-strain curves; b) the interface de-bonded length of $2 l_{\mathrm{d}} / l_{\mathrm{c}}$ versus the applied stress curves; c) the interface oxidation ratio of $\zeta / l_{\mathrm{d}}$ versus the applied stress curves; d) the broken fibre fraction versus the applied stress curves of the $3 \mathrm{D} \mathrm{C} / \mathrm{SiC}$ composite. 
- When the pre-exposure temperature and time increase, the composite tensile strength and failure strain both decrease; the interface de-bonded length and the interface oxidation ratio both increase; and the fibre broken fraction increases at the low applied stress level.

- When the interface shear stress increases, the composite failure strain decreases; the interface de-bonded length decreases, and the interface oxidation ratio increases.

- When the fibre strength and Weibull modulus increase, the composite tensile strength and failure strain both increase; and the fibre broken fraction decreases at the low applied stress level.

\section{Acknowledgements}

The work reported here is supported by the Fundamental Research Funds for the Central Universities (Grant No. NS2019038).

\section{REFERENCES}

1. Ohnabe H., Masaki S., Onozuka M., Miyahara K., Sasa T. (1999): Potential application of ceramic matrix composites to aero-engine components. Composites Part A: Applied Science and Manufacturing, 30(4), 489-496. doi: 10.1016/ S1359-835X(98)00139-0

2. Bouillon E., Ojard G., Ouyang Z., Zawada L., Habarou G., Louchet C., Feindel D., Spriet P., Logan C., Arnold T., Rogers K., Stetson D. (2005). Post engine characterization and flight test experience of self sealing ceramic matrix composites for nozzle seals in gas turbine engines. In: ASME Turbo Expo 2005: Power for Land Sea and Air, Reno Nevada, ASME68428.

3. Halbig M.C., Jaskowiak M.H., Kiser J.D., Zhu D. (2013). Evaluation of ceramic matrix composite technology for aircraft turbine engine applications. NASA Report, No. 20130010774.

4. Li L. (2018). Damage, fracture and fatigue of ceramicmatrix composites. Springer Nature Singapore.

5. Li L., Song Y., Sun Y. (2013): Modeling the tensile behavior of unidirectional $\mathrm{C} / \mathrm{SiC}$ ceramic-matrix composites. Mechanics of Composite Materials, 49(6), 659-672. doi: 10.1007/s11029-013-9382-y

6. Li L., Song Y., Sun Y. (2015): Modeling the tensile behavior of cross-ply $\mathrm{C} / \mathrm{SiC}$ ceramic-matrix composites. Mechanics of Composite Materials, 51(3), 359-376. doi: 10.1007/ s11029-015-9507-6

7. Li L.(2018): Modeling the monotonic and cyclic tensile stress-strain behavior of $2 \mathrm{D}$ and $2.5 \mathrm{D}$ woven $\mathrm{C} / \mathrm{SiC}$ ceramic-matrix composites. Mechanics of Composite Materials, 54, 165-178. doi: 10.1007/s11029-018-9729-5
8. Wang Y., Zhang L., Cheng L. (2013): Comparison of tensile behaviors of carbon/ceramic composites with various fiber architectures. International Journal of Applied Ceramic Technology, 10(2), 266-275. doi: 10.1111/j.1744-7402. 2011.02727.x

9. Zhang C., Zhao M., Liu Y., Wang B., Wang X., Qiao S. (2016): Tensile strength degradation of a $2.5 \mathrm{D}-\mathrm{C} / \mathrm{SiC}$ composite under thermal cycles in air. Journal of the European Ceramic Society, 36(12), 3011-3019. doi: 10.1016/j.jeurceramsoc.2015.12.007

10. Mei H., Cheng L., Zhang L. (2006): Thermal cycling damage mechanisms of $\mathrm{C} / \mathrm{SiC}$ composites in displacement constraint and oxidizing atmosphere. Journal of the American Ceramic Society, 89, 2330-2334. doi: 10.1111/j.15512916.2006.01012.x

11. Halbig M.C., Cawley J.D. (2000). Modeling the oxidation kinetics of continuous carbon fibers in a ceramic matrix. NASA/TM-2000-209651.

12. Halbig M.C., McGuffin-Cawley J.D., Eckel A.J., Brewer D.N. (2008):Oxidation kinetics and stress effects for the oxidation of continuous carbon fibers within a microcracked $\mathrm{C} / \mathrm{SiC}$ ceramic matrix composite. Journal of the American Ceramic Society, 91,519-526. doi: 10.1111/j.15512916.2007.02170.x

13. Hou J., Qiao S., Zhang C., Zhang Y. (2009): The influence of high temperature exposure to air on the damage to 3D-C/SiC composites. New Carbon Materials, 24, 173-177. doi: 10.1016/S1872-5805(08)60046-3

14. Wallentine S.M. (2015). Effect of prior exposure at elevated temperatures on tensile properties and stress-strain behavior of four non-oxide ceramic matrix composites. Master Thesis, Air Force Institute of Technology.

15. Gowayed Y., Abouzeida E., Smyth I., Ojard G., Ahmad J., Santhosh U., Jefferson G. (2015): The role of oxidation in time-dependent response of ceramic-matrix composites. Composites Part B: Engineering, 76, 20-30. doi: 10.1016/j. compositesb.2015.02.005

16. Casas L., Martinez-Esnaola J.M. (2003): Modeling the effect of oxidation on the creep behavior of fiber-reinforced ceramic matrix composites. Acta Materialia, 51, 3745-3757. doi: 10.1016/S1359-6454(03)00189-7

17. Curtin W.A. (1993): Multiple matrix cracking in brittle matrix composites. Acta Metallurgica et Materialia, 41(5), 1369-1377. doi: 10.1016/0956-7151(93)90246-O

18. Gao Y, Mai Y, Cotterell B. (1988): Fracture of fiber-reinforced materials. Journal of Applied Mathematics and Physics, 39,550-572. doi: 10.1007/BF00948962

19. Curtin W.A. (1991): Theory of mechanical properties of ceramic-matrix composites. Journal of the American Ceramic Society, 74(11), 2837-2845. doi: 10.1111/j.1151-2916. 1991.tb06852.x

20. Lara-Curzio E. (1999): Analysis of oxidation-assisted stress-rupture of continuous fiber-reinforced ceramic matrix composites at intermediate temperatures. Composites Part A: Applied Science and Manufacturing, 30(4), 549-554. doi: 10.1016/S1359-835X(98)00148-1 